\title{
Review Article \\ Serum Biomarkers Identification by Mass Spectrometry in High-Mortality Tumors
}

\author{
Alessandra Tessitore, Agata Gaggiano, Germana Cicciarelli, Daniela Verzella, \\ Daria Capece, Mariafausta Fischietti, Francesca Zazzeroni, and Edoardo Alesse \\ Department of Biotechnological and Applied Clinical Sciences, University of L'Aquila, Via Vetoio Coppito 2, \\ 67100 L'Aquila, Italy \\ Correspondence should be addressed to Edoardo Alesse; edoardo.alesse@univaq.it
}

Received 10 August 2012; Revised 16 November 2012; Accepted 11 December 2012

Academic Editor: Visith Thongboonkerd

Copyright (C) 2013 Alessandra Tessitore et al. This is an open access article distributed under the Creative Commons Attribution License, which permits unrestricted use, distribution, and reproduction in any medium, provided the original work is properly cited.

\begin{abstract}
Cancer affects millions of people worldwide. Tumor mortality is substantially due to diagnosis at stages that are too late for therapies to be effective. Advances in screening methods have improved the early diagnosis, prognosis, and survival for some cancers. Several validated biomarkers are currently used to diagnose and monitor the progression of cancer, but none of them shows adequate specificity, sensitivity, and predictive value for population screening. So, there is an urgent need to isolate novel sensitive, specific biomarkers to detect the disease early and improve prognosis, especially in high-mortality tumors. Proteomic techniques are powerful tools to help in diagnosis and monitoring of treatment and progression of the disease. During the last decade, mass spectrometry has assumed a key role in most of the proteomic analyses that are focused on identifying cancer biomarkers in human serum, making it possible to identify and characterize at the molecular level many proteins or peptides differentially expressed. In this paper we summarize the results of mass spectrometry serum profiling and biomarker identification in high mortality tumors, such as ovarian, liver, lung, and pancreatic cancer.
\end{abstract}

\section{Introduction}

Cancer-related mortality is one of the leading causes of death worldwide. The most effective treatment to fight cancer is still early diagnosis. On the other hand, it is known that the correct classification of the tumor, coupled to a suitable therapy and to a stringent follow-up, helps to prevent and detect relapses. Cancer is a very heterogeneous disease, and, at the diagnostic level, is defined by many indexes such as histological grade, tumor stage, patient age, sex and, more importantly, genetic background and profiles. Histological evaluation of tumor specimens obtained from tissue biopsy is the gold standard of diagnosis, but often tumors with the same histopathological features respond differently to the same therapy. New generation diagnostic platforms, previously unavailable, have enabled to better characterize transcriptomic signatures that predict tumor behaviour, helping to define diagnosis, prognosis, and the most appropriate therapies [1-3]. Tumor biomarker discovery in biological fluids, such as serum, plasma, and urine, is one of the most challenging aspects of proteomic research [4]. Many researchers have attempted to identify biomarkers in serum that reflect a particular pathophysiological state. Since the expressed proteins, native, fragmented, or posttranslationally modified, quickly change in response to environmental or pathological stimuli, the serum proteome is considered dynamic, oppositely to the stable nature of the genome. Proteins and their functions can determine the phenotypic diversity that arises from a set of common genes. The study of the serum proteome highlights differences in protein expression reflecting a specific pathological state and provides useful information to diagnose a disease, to evaluate prognosis or therapy response [5].

\section{Biomarker Discovery in Cancer: The Complexity of Human Serum}

Single or a small number of serum-based biomarkers indicative of cancer progression, such as prostate-specific antigen (PSA), alpha-fetoprotein (AFP), CA-125, CA-15.3, CA-19-9, or CEA for prostate, liver, ovary, breast, pancreas, or colon 
cancer, are currently used. Most of these molecules have been isolated from animals immunized with tumor cells extracts or cell lines, with subsequent screening for monoclonal antibodies against cancer-associated antigens [6]. The abovementioned proteins increase the accuracy of diagnosis, even though there is an urgent need to isolate and use in clinical practice more specific biomarkers, or groups of biomarkers, to precisely characterize the disease at the diagnostic or prognostic level and to monitor its progression [7, 8]. Biomarkers could also help to predict the response of the patient to anticancer therapy and thereby to guide physicians in choosing the best treatment. This research is more appealing due to the simplicity of obtaining blood samples, but, at the same time, shows limits due to the complexity of the serum protein mixtures. A plethora of molecules from almost every tissue of the body can be found in human serum/plasma. Many of the serum proteins are present at very low concentrations (less than $\mathrm{pg} / \mathrm{mL}$ ), while others are present in very large amounts (more than $\mathrm{mg} / \mathrm{mL}$ ). Serum and plasma are very complex mixtures of proteins and exhibit a broad dynamic range of relative abundance (up to 12 orders of magnitude) [9]. They contain thousands of proteins, whose some are very abundant (e.g., albumin, immunoglobulins, apolipoproteins) and constitute approximately the $95 \%$ of the total protein content, but only the $0.1 \%$ of total protein species $[10,11]$. For these reasons, it is thought that many potentially important proteins and markers, if present at low concentrations, can escape the detection. Evidences show that the circulating fragments from unmodified or post-translationally modified proteins generated in the tumor tissue microenvironment can be used as diagnostic or prognostic markers. Proteolysis within the tissue or deregulated post-translational events (e.g. phosphorylation) generate protein fragments that diffuse into the circulation and could give information about the presence or the progression of the disease, then facilitating the management of the tumor. Among these fragments, the fraction with low molecular weight, the peptidome $(<20 \mathrm{KDa}$, LMW peptides), is protected from renal clearance by interaction with abundant serum proteins and, in particular, seems to be an important source of biomarkers [12].

In order to simplify the biomarker discovery process, many prefractionation methods have been developed to remove highly abundant proteins. These useful precursors of proteomic analysis include the use of immobilized dyes (cibacron blue) [13, 14], immunoaffinity-based techniques $[15,16]$, solid phase fractionation [17], liquid chromatography [18], or low-molecular weight fraction enrichment [19-21]. A promising method under investigation is based on the use of N-isopropylacrylamide (NIPA) nanoparticles which allow a fast one-step capture and concentration of analytes less than 20-25 KDa in molecular weight [22-24]. At the same time, the nanoparticles are able to protect the proteins from the degradation due to the "ex vivo" enzymatic activity of serum proteases, and, when conjugated with suitable chemical baits, show higher capability to sequester and retain many different proteins from whole serum, on the basis of their chemical and physical properties [25]. With this method, the captured analytes can be recovered by a simple electroelution and then analyzed by HPLCMS/MS, western blotting or immunoassays for complete molecular characterization. To reduce the complexity of serum proteome, several studies are focused on targeting a specific subset of serum proteins [26]. Glycosylation is one of the most common posttranslational modifications in proteins. Approximately 50\% of known eukaryotic proteins are glycosylated [27]. It is known that cancer cells express aberrant glycosylation patterns [28]. The analysis of glycosylated proteins (glycoproteome) has received great interest, because of the glycoproteic nature of the currently used cancer biomarkers. Two major methods have been developed to enrich glycoproteins or glycopeptides, based on chemical capture (reaction between aldehyde groups and hydrazide) $[29,30]$ and lectin-affinity capture (specific recognition of protein glycan moieties by lectins) [31].

\section{Mass Spectrometry: The Cancer Biomarker Discovery Tool}

Many studies have been focused on the identification of new serum biomarkers by mass spectrometry (MS). This powerful method enables to identify a protein without requiring the knowledge of its amino acid sequence. Further improvement of this technology has provided high accuracy to define mass-to-charge ratio $(\mathrm{m} / \mathrm{z})$ and to generate highresolution spectra. In addition, the development of tandem mass spectrometry (MS/MS), able to provide de novo protein sequence information, has enhanced the applications of this technology in proteomics $[32,33]$. Several MS methods have been used to characterize body fluids. Different combinations of ionization sources (e.g., MALDI, ESI), analysers (e.g., time of flight TOF, quadrupole, Fourier transform and quadrupole ion traps), and fragmentation methods (e.g., CID collision induced dissociation, ETD electron transfer dissociation) can be used. MALDI-TOF (Matrix-Assisted Laser Desorption/Ionization-time of flight) [34] is based on a soft ionization method where a laser beam generates evaporation of a crystallized sample-matrix mixture. MALDI is used in biochemical areas for the analysis of proteins, peptides and oligonucleotides. SurfaceEnhanced Laser Desorption/Ionization Time-of-Flight (SELDI-TOF), a modification of MALDI-TOF, allows the identification of proteins differentially expressed in serum by applying a small amount of sample directly on an array surface involving various chromatographic models based on classical chemistries (i.e., normal phase, hydrophobic, cationand anion-exchange), affinity-coated surfaces (IMAC, immobilized metal affinity capture), or biomolecular affinity probes $[5,35,36]$, with minimal requirements for purification and separation [37]. Selectively retained proteins are analyzed by laser desorption and subsequent ionization. The results are shown by a mass spectrum identifying $m / z$ ratios and peak intensities of peptides/proteins. Data preprocessing (i.e., calibration, baseline correction, normalization, peak detection, and alignment), bioinformatic and statistical analyses are performed in order to highlight and characterize any protein differentially expressed. SELDI-TOF allows the detection of many low molecular weight proteins [38]. 
Liquid chromatography/electrospray ionization tandem mass spectrometry (HPLC/ESI-MS/MS) technology is an alternative approach for serum biomarker identification. The mixtures of analytes are subjected to HPLC then the solution is nebulized under atmospheric pressure and exposed to a high electrical field which generates a charge on the droplets' surface [39]. Due to the evaporation, droplets become much smaller and enter into the analyzer. HPLC-ESI-MS/MS couples protein fractionation with mass spectrometry, where peptide sequence tags can be produced from peptide fragments. Tandem mass spectrometry and data analysis by suitable bioinformatic tools, algorithms and databases, provides a powerful method to characterize peptides at the aminoacidic level, allowing a highly refined analysis [40].

The use of mass spectrometry for serum biomarker discovery is quite simple: spectral peaks (plots representing on the $x$-axis the $m / z$ ratios of ions, and on the $y$-axis the detected ion abundance), are identified in a pathological group and compared with those obtained from normal control groups. Differences in spectral profiles detect putative biomarkers. Essentially four strategies have been used in MS biomarker discovery: analysis of polypeptides separated by electrophoresis or chromatography, with or without prior fragmentation; analysis of enzymatic peptide fragments separated by HPLC and then analyzed by ESI or MALDI; analysis of proteins adsorbed on a solid surface; and analysis of specific serum fractions, such as the peptidome or the glycoproteic fraction [4].

Due to the lack of effective screening test, these methods have been applied to the serum biomarker discovery in many tumors, including those with high mortality, such as ovary, lung, liver, and pancreatic cancer. Here we report the results of studies focused on serum biomarker identification in the above-mentioned types of cancer. Several protein profiles and specific proteins (Tables 1, 2, 3, and 4) have been characterized and classified as putative biomarkers.

3.1. Serum Biomarkers in Ovarian Cancer. Despite advances in cancer therapy, mortality due to ovarian cancer is almost unmodified during the last decades [50]. Ovarian cancer is usually diagnosed at a late clinical stage in more than $80 \%$ of patients [51]. In this group, the 5-year survival is approximately $35 \%$. By contrast, the 5-year survival for patients with stage I ovarian cancer is more than $90 \%$ and surgery alone can be used as elective therapy [52]. Cancer antigen 125 (CA-125) is the most widely used biomarker for ovarian cancer. Elevated levels of CA-125 are detected in about $80 \%$ of patients with advanced-stage disease, but they are increased in only $50-60 \%$ of patients with early stage ovarian cancer [53]. The calculated positive predictive value for CA-125, considered as a single marker, is less than $10 \%$, but this value was improved by ultrasound screening methods [54].

3.1.1. Proteomic Patterns for Ovarian Cancer Detection. Analysis of sera by TOF-MS provided specific signature patterns which can be compared to distinguish ovarian cancer from benign disease or normal individuals. A training set of 50 sera from unaffected women and 50 from patients with ovarian cancer were analyzed by SELDI/TOF by using
TABLE 1: ovarian cancer serum biomarkers identified after MS-based studies.

\begin{tabular}{|c|c|c|}
\hline Putative ovarian cancer biomarker & $\begin{array}{c}\text { Expression } \\
\text { in ovarian } \\
\text { ca sera }\end{array}$ & References \\
\hline Apolipoprotein I & Decreased & {$[36,41]$} \\
\hline Transthyretin & Decreased & {$[36,41]$} \\
\hline $\begin{array}{l}\text { Inter- } \alpha \text {-trypsin inhibitor heavy chain } \mathrm{H} 4 \\
\text { (cleavage fragment) }\end{array}$ & Increased & {$[36]$} \\
\hline Haptoglobin- $\alpha$ chain & Increased & {$[42]$} \\
\hline Haptoglobin I precursor & Increased & {$[43]$} \\
\hline Fibrinopeptide A & Increased & {$[44]$} \\
\hline Serum amyloid A1 & Increased & {$[45]$} \\
\hline Hemoglobin $\alpha$ and $\beta$ chain & Increased & {$[41,46]$} \\
\hline Transferrin & Decreased & {$[41]$} \\
\hline Keratin 2a & Increased & {$[47]$} \\
\hline Glycosyltransferase-like 1B & Increased & {$[47]$} \\
\hline Complement component 3 precursor & Decreased & {$[47]$} \\
\hline Complement component $4 \mathrm{~A}$ preprotein & Decreased & {$[47]$} \\
\hline Casein kinase II alpha 1 subunit isoform a & Decreased & {$[47]$} \\
\hline D-amino-acid oxidase & Decreased & {$[47]$} \\
\hline Transgelin 2 & Increased & {$[47]$} \\
\hline Inter-alpha (globulin) inhibitor H4 & Increased & {$[47]$} \\
\hline $\begin{array}{l}\text { Fibrinogen, alpha chain isoform alpha } \\
\text { preprotein }\end{array}$ & Increased & {$[47]$} \\
\hline CC2 motif ligand 18 (CCL18) & Increased & {$[48]$} \\
\hline CXC motif ligand 1 (CXCL1) & Increased & {$[48]$} \\
\hline $\begin{array}{l}\text { Connective tissue-activating peptide III } \\
\text { (CTAPIII) }\end{array}$ & Decreased & {$[49]$} \\
\hline Platelet factor 4 (PF4) & Decreased & [49] \\
\hline
\end{tabular}

a C16 hydrophobic interaction protein chip. An algorithm identified a proteomic pattern able to distinguish cancer from non-cancer subjects. The pattern was then used to differentiate an independent set of 116 samples (50 ovarian cancer, 66 non-malignant disease or unaffected), yielding $100 \%$ sensitivity and $95 \%$ specificity [67]. Some of the characteristic ion peaks in the previous signature have been sequenced and described in an independent cohort of ovarian cancer sera [36]. One hundred nine serum samples from ovarian cancer patients, 19 sera from individuals with benign tumors, and 56 from healthy donors were analyzed on strong anion-exchange surface using SELDI-TOF. Three panels of candidate protein biomarkers were obtained (1st: $4.4 \mathrm{kDa}, 15.9 \mathrm{kDa}, 18.9 \mathrm{kDa}$, $23 \mathrm{kDa}, 30.1 \mathrm{kDa}-95.7 \%$ sensitivity, $82.6 \%$ specificity; $2 \mathrm{nd}$ : $3.1 \mathrm{kDa}, 13.9 \mathrm{kDa}, 21.0 \mathrm{kDa}, 79.0 \mathrm{kDa}$, and $106.7 \mathrm{kDa}-81.5 \%$ sensitivity, $94.9 \%$ specificity; 3rd: $5.1 \mathrm{kDa}, 16.9 \mathrm{kDa}, 28 \mathrm{kDa}$, $93 \mathrm{kDa}-72.8 \%$ sensitivity, $94.9 \%$ specificity). The protein panels correctly diagnosed $41 / 44$ blind test samples: $21 / 22$ malignant ovarian cancers, 6/6 low malignant potential tumors, 5/6 benign tumors, $9 / 10$ normal individuals [68]. A four-peak model $(\mathrm{m} / z$ 6195, 6311, 6366, 11498), performing better than CA-125, has been identified for diagnosis or monitoring of the therapy in ovarian cancer. This study 
TABLE 2: Liver cancer serum biomarkers identified after MS-based studies.

\begin{tabular}{|c|c|c|}
\hline Putative liver cancer biomarker & $\begin{array}{c}\text { Expression } \\
\text { in liver ca } \\
\text { sera } \\
\end{array}$ & References \\
\hline Complement c3 & Increased & {$[55]$} \\
\hline Histidine rich glycoprotein & Increased & {$[55]$} \\
\hline CD14 & Increased & {$[55]$} \\
\hline Hepatocyte growth factor & Increased & {$[55]$} \\
\hline $\begin{array}{l}\text { C-terminal part of vitronectin V10 } \\
\text { fragment }\end{array}$ & Increased & {$[56]$} \\
\hline Protein complement C3a & Increased & {$[57]$} \\
\hline Annexin VI isoform & Increased & {$[58]$} \\
\hline Complement component 9 & Increased & {$[58]$} \\
\hline Ceruloplasmin & Increased & {$[55,58]$} \\
\hline Serum amyloid A4 & Increased & {$[58]$} \\
\hline Serum amyloid A2 & Increased & {$[58]$} \\
\hline Serum amyloid $\mathrm{A} 1$ isoform 2 & Increased & {$[58]$} \\
\hline Cystatin C & Increased & [59] \\
\hline Neutrophil-activating peptide 2 & Increased & {$[60]$} \\
\hline Thrombin light chain & Increased & {$[61]$} \\
\hline $\begin{array}{l}\text { Growth-related oncogene alpha } \\
\text { (GRO-alpha) }\end{array}$ & Increased & {$[61]$} \\
\hline Alpha-1 acid glycoprotein & Increased & {$[62]$} \\
\hline Haptoglobin & Increased & {$[63]$} \\
\hline $\mathrm{N}$ terminus complement $\mathrm{C} 3 \mathrm{f}$ & Decreased & {$[64]$} \\
\hline Fibrinopeptide & Decreased & {$[64]$} \\
\hline Complement $\mathrm{C} 4$ alpha peptides & Increased & {$[64]$} \\
\hline Zyxin peptide & Increased & {$[64]$} \\
\hline Coagulation factor XIII peptide & Increased & {$[64]$} \\
\hline Biliverdin diglucuronide & Increased & {$[64]$} \\
\hline Heat-shock protein 27 & Increased & {$[65]$} \\
\hline MYH2 protein & Increased & {$[66]$} \\
\hline Mitochondrial ATP synthase & Increased & {$[66]$} \\
\hline Sulphated glycoprotein-2 & Increased & {$[66]$} \\
\hline Glial fibrillary acidic protein & Increased & {$[66]$} \\
\hline
\end{tabular}

TABLE 3: Lung cancer serum biomarkers identified after MS-based studies.

\begin{tabular}{lcc}
\hline Putative lung cancer biomarker & $\begin{array}{c}\text { Expression in lung } \\
\text { ca sera }\end{array}$ & References \\
\hline Serum amyloid protein A & Increased & {$[71-76]$} \\
Haptoglobin alpha subunit & Increased & {$[77]$} \\
Hepatocyte growth factor & Increased & {$[77]$} \\
Transthyretin & Decreased & {$[75,78]$} \\
Alpha-1 acid glycoprotein 1 and 2 & Increased & {$[74]$} \\
Apolipoprotein A4 peptides & Increased/decreased & {$[79]$} \\
Fibrinogen alpha chain & Increased & {$[79]$} \\
Limbin & Increased & {$[79]$} \\
\hline
\end{tabular}

was conducted on a training ( 31 primary cancer, 16 benign ovarian disease, 25 healthy controls) and a blind test set ( 23
TABLE 4: Pancreatic cancer serum biomarkers identified after MSbased studies.

\begin{tabular}{lcc}
\hline & $\begin{array}{c}\text { Expression } \\
\text { in } \\
\text { Putative pancreatic cancer biomarker }\end{array}$ & $\begin{array}{c}\text { Rancreatic } \\
\text { ca sera }\end{array}$ \\
\hline Apolipoprotein CIII & Increased & {$[82]$} \\
Serum amyloid protein A & Increased & {$[83]$} \\
Apolipoprotein A-II & Decreased & {$[84]$} \\
Apolipoprotein A-I & Decreased & {$[84]$} \\
Transthyretin & Decreased & {$[84]$} \\
Alpha-2 macroglobulin & Increased & {$[85]$} \\
Ceruloplasmin & Increased & {$[85]$} \\
Complement 3C & Increased & {$[85]$} \\
Platelet factor 4 & Decreased & {$[86]$} \\
Mannose-binding lectin 2 & Increased & {$[87]$} \\
Myosin light chain kinase 2 & Increased & {$[87]$} \\
CXC chemokine ligand 7 & Decreased & {$[88]$} \\
TIMP1-ICAM1 & Increased & {$[89]$} \\
Alpha-1 antitrypsin & Increased & {$[90]$} \\
Fibrinogen gamma & Increased & {$[91]$} \\
C14orf166 & Increased & {$[92]$} \\
Alpha-1 antichymotrypsin & Increased & {$[93]$} \\
\hline
\end{tabular}

ovarian cancer, 15 benign, 5 normal). The four peak model showed a sensitivity of $90.8 \%$ and a specificity of $93.5 \%$ in the training set, and a sensitivity of $87 \%$ and a specificity of $95 \%$ in the blind test set in discriminating cancer from non cancer patients [69]. Hocker et al. [70] analyzed mass spectrometry peak differences in 35 ovarian cancer patients and 16 disease-free subjects. Proteomic profiles distinguished early-stage from advanced cancer with a sensitivity of $80 \%$ and a specificity of $93 \%$.

3.1.2. Glycoproteomics in Ovarian Cancer. An et al. [80] developed a glycomic approach to identify oligosaccharide markers for ovarian cancer by analyzing ovary cell lines supernatants and then confirming their presence in sera from patients and healthy controls. Changes in glycosilation were monitored by MALDI-Fourier Transform Ion Cyclotron Resonance-MS. Approximately 15 unique serum glycan markers were detected in all patients and were absent in controls. Leiserowitz et al. [81] analyzed glycan markers and CA-125 levels in 48 sera from ovarian cancer women and 24 controls. Oligosaccharides were cleaved from serum glycoproteins and isolated using solid phase extraction. MALDI-Fourier Transformation-MS was used to identify peaks. Sixteen unique oligosaccharide signals were identified in most of the cancer patients (44/48) and just in $1 / 24$ controls (sensitivity $91.6 \%$, specificity $95.8 \%$ ).

3.1.3. Ovarian Cancer Biomarker Proteins Involved in Inflammatory Processes. Several proteins involved in inflammatory processes and acute-phase response have been identified as putative biomarkers for ovarian cancer. In a study by 
Zhang et al. [36], sera were fractionated by anion exchange chromatography. Aliquots were bound in triplicate with a randomized chip/spot allocation scheme to IMAC3-Cu, SAX2, H50, and WCX2 protein chip array. For biomarker identification, proteins were purified, separated by SDSPAGE, and analyzed by MS/MS. Three proteins/protein fragments, described as acute-phase reactants (apolipoprotein A1, $m / z 28043$, a truncated form of transthyretin, $m / z 12828$, and a fragment of inter- $\alpha$-trypsin inhibitor heavy chain $\mathrm{H} 4$, $m / z 3272$ ), were identified as putative biomarkers able to improve the detection of early stage ovarian cancer [36]. Ye et al. [42] identified by SELDI an $11.7 \mathrm{kDa}$ peak showing higher intensity in cancer sera. After protein purification and LC-MS/MS analysis, the alpha chain of haptoglobin, an acute phase reactant, was identified and further validated by western blot and ELISA as a potential biomarker for ovarian cancer, by using a specific polyclonal antibody against the peptide identified by MS/MS analysis. The marker was 2 -foldexpressed in cancer sera and had 64\% sensitivity and 90\% specificity when used alone, or $91 \%$ and $95 \%$ sensitivity and specificity, if combined with CA-125. After high abundance protein removal and two-dimensional gel electrophoresis (2-DE), Ahmed et al. [43] performed nanoelectrospray quadrupole-quadrupole time of flight mass spectrometry (nESIQ-(q)TOF-MS) and MALDI/TOF analysis on six protein spots over-expressed in cancer sera. Protein isoforms of haptoglobin-I precursor (HAPI), a liver glycoprotein present in human serum, were identified as putative novel biomarkers and confirmed by 2-DE and western blotting on the serum from healthy controls and grade 1 and 3 ovarian cancer patients. Bergen III et al. [44] analyzed by nano-LC-ESITOF-MS or Fourier Tranform Ion Cyclotron Resonance (FTICR) the low molecular weight serum fraction obtained by ultrafiltration and identified several candidate biomarkers. Among these, the fibrinopeptide-A, already described as involved in acute phase reactions and elevated in many cancer including ovary, was detected. Two peaks (11.7 and $11.5 \mathrm{kDa})$ were identified by SELDI-TOF in thermostable plasma fractions from 27 ovarian cancer and 34 control sera. A method involving cysteine modifications, 2-DE, and HPLC allowed to characterize the peaks corresponding to serum amyloid A1, an acute phase reactant, and its N-terminal arginine truncated form [45]. Kozak et al. [41] identified by microLC-MS/MS four biomarkers for early stage ovarian cancer (transthyretin, apolipoprotein A1, transferrin, and betahemoglobin), corresponding to already described 13.9-TTR-, 12.9-TTR-, 15.9-Hb-, 28-ApoAI-, 79-Tf-kDa SELDI peaks [68]. Differential expression of these proteins in sera was also confirmed by western blot and ELISA. Lopez et al. [47] set-up a workflow using carrier protein-bound affinity enrichment of serum samples directly coupled with MALDI/TOF. Subsequent tandem MS analysis defined the serum protein-bound peptides' sequence. The procedure was able to identify several specific biomarker panels to differentiate stage I ovarian cancer from unaffected and age-matched women. Among the peptides identified, proteins involved in inflammatory processes (complement component 3 precursor, complement component $4 \mathrm{~A}$ preprotein, inter-alpha globulin inhibitor $\mathrm{H} 4$ ), as well as the glycosyltransferase-like $1 \mathrm{~B}$, a peroxisomal oxidation enzyme (D-amino-acid oxidase), two proteins involved in cancerogenesis (transgelin 2, casein kinase II alpha 1 subunit isoform a), fibrinogen alpha chain isoform alpha preprotein, and keratin 2 a were described as putative biomarkers. In a study on sera from patients with ovarian cancer, compared with sera from patients with benign masses or different type of cancer, it has been shown that the chemokines CC2 motif ligand 18 (CCL18) and CXC motif ligand 1 (CXCL1), identified by MALDI-MS/MS analysis and further validated by ELISA, can be considered as novel circulating tumor markers for differential diagnosis between ovarian cancer and benign masses (sensitivity $92 \%$, specificity 97\%) [48]. A nested case-control study performed on 295 sera from women pre-dating their ovarian cancer diagnosis and 585 matched control samples, showed that two peaks identified by MALDI, described as the connective tissue-activating peptide III (CTAPIII) and the platelet factor 4 (PF4), can be associated with CA-125 to improve early diagnosis [49].

\subsubsection{Ovarian Cancer Biomarker Proteins Involved in Other} Functions. Woong-Shick et al. [46] studied by SELDI-TOF 35 sera from ovarian cancer patients in comparison to 10 from normal women. After protein purification and N-terminal sequencing, hemoglobin- $\alpha$ and $\beta$ chains were described as corresponding to the most distinctive peaks differentially expressed (15.1 and $15.8 \mathrm{kDa})$. ELISA validation test for intact hemoglobin indicated a sensitivity of $77 \%$ in sera from ovarian cancer patients. As above-mentioned, hemoglobin was also described as a putative ovarian cancer biomarker in a study by Kozak et al. [41].

3.2. Serum Biomarkers in Liver Cancer. Liver cancer is often diagnosed at very late stage and is associated to poor prognosis, high recurrence and mortality. Hepatocellular carcinoma (HCC), the most frequent liver neoplasm, is the fifth most common cancer, affecting approximately one million people every year, with an incidence almost corresponding to death rate [94] and a 5 year survival ranging from $17 \%$ to $50 \%$. Some predisposing factors, such as viral infections [95], diabetes, metabolic syndromes, exposition to aflatoxin, or alcohol consumption, are frequently related to liver tumor initiation. This allows a management of the patients at risk, making it possible in some cases to diagnose the disease earlier. The most important liver cancer serum biomarker is alpha-fetoprotein (AFP), an oncofetal glycoprotein with elevated levels in patients affected by cirrhosis and HCC. The sensitivity and specificity of AFP range between $60-80 \%$ and 70-90\%, respectively [96]. For this reason, AFP test utility for screening procedures is questionable. Many studies have been focused on characterizing differentially expressed proteins in sera from patients affected by liver cancer or predisposing diseases and, similarly to ovarian cancer, proteomic profiles and proteins have been identified.

3.2.1. Proteomic Patterns for Liver Cancer Detection. A total number of $117 \mathrm{HCV}$-positive sera from 39 patients affected by low-grade fibrosis, 44 with cirrhosis without HCC, and 34 with both cirrhosis and HCC were preprocessed by anionexchange fractionation and analyzed by SELDI-TOF. A four 
markers panel $(7486,12843,44293,53598 \mathrm{Da})$ identified HCC with a sensitivity of $100 \%$ and a specificity of $85 \%$ in a two-way comparison of HCV-cirrhosis versus HCVHCC training set. Sensitivity and specificity for the correct identification of HCC were $68 \%$ and $80 \%$ for random test samples. Fibrosis patients were distinguished from cirrhotic using a five marker panel $(2873,6646,7775,10525,67867 \mathrm{Da}$, sensitivity and specificity $100 \%$ and $85 \%, 80 \%$ and $67 \%$ in the training and random test samples, resp.). After purification, MS/MS analysis and immunoassay validation, the $6646 \mathrm{Da}$ protein was identified as apolipoprotein C-I and described as a marker to differentiate liver fibrosis from cirrhosis [97]. SELDI-TOF protein-chip technology was applied to analyze sera from patients affected by HCV-associated chronic liver diseases with (64 samples) or without (77 samples) HCC. Samples were randomly split into two analysis groups. Six selected protein peaks $(\mathrm{m} / z$ 3444, 3890, 4067, 4435, 4470, 7770) gave information to perform early diagnosis and to distinguish HCC from chronic liver disease in the absence of HCC (sensitivity and specificity $83 \%$ and $76 \%$ ). The model was also applied to the analysis of sera from 5 subjects HCCfree and from 7 HCC patients collected before the diagnosis by ultrasonography. The markers allowed to correctly predict the presence of HCC in 6/7 patients [98]. Wu et al. [99] identified serum proteins and peptide profiles to differentiate HBVrelated HCC and HBV-related cirrhosis. Forty-five protein peaks distinguished HCC from LC (liver cirrhosis) samples. The most significant SELDI $3892 \mathrm{~m} / z$ peak showed sensitivity and specificity of $69 \%$ and $83 \%$ and was identified also in six AFP-negative patients. The 3892 peak was considered as a complementary diagnostic marker or a potential marker for positive or negative $\alpha$-fetoprotein HCC. SELDI-TOF analysis of sera from 120 patients affected by HCC and 120 affected by cirrhosis showed five proteomic peaks $(\mathrm{m} / z$ 3324, 3994, 4665,4795 , and 5152) able to achieve, especially for early stage HCC, a diagnostic value better than serum AFP $(83 \%$ sensitivity and $92 \%$ specificity in the test set) [100]. Cui et al. [101] formulated classification trees, based on SELDI serum protein profiles, able to distinguish patients affected by chronic hepatitis B, cirrhosis, and HCC from healthy individuals. Samples were divided into training and testing groups, each composed by HBV, liver cirrhosis, HCC patients matched with normal controls. Decision trees distinguished HCC with $90 \%$ sensitivity and $89 \%$ specificity, cirrhosis with $100 \%$ sensitivity and $86 \%$ specificity, and HBV patients with $85 \%$ sensitivity and $84 \%$ specificity.

3.2.2. Glycoproteomics in Liver Cancer. Goldman et al. [102] used a glycomic approach to evaluate the abundance of $83 \mathrm{~N}$-glycans in a total of 202 sera from 73 HCC patients, 52 with chronic liver disease and 77 controls. Glycans were enzymatically obtained from serum and permethylated before MALDI-TOF analysis. The abundance of $57 \mathrm{~N}$-glycans resulted significantly altered in HCC samples. Six glycans were used to differentiate HCC cases from controls and showed sensitivity and specificity of $73-90 \%$ and $36-91 \%$, respectively. A combination of three $\mathrm{N}$-glycans $(\mathrm{m} / z$ 2472.9, $3241.9,4052.2$ ) was able to classify HCC with $90 \%$ and $89 \%$ sensitivity and specificity in an independent validation set of patients with chronic liver disease. Two-hundred and three serum samples collected from 73 HCC cases, 52 chronic liver disease, and 78 healthy subjects were treated for $\mathrm{N}$-glycans releasing and then analyzed by MALDI. Seven glycan peaks achieved good performance in distinguishing HCC from chronic liver disease patients and normal individuals [103]. After depletion of high abundance proteins, Liu et al. [55] analyzed 27 sera from early HCC in comparison to 27 cirrhosis patients in order to identify glycoprotein biomarkers. A lectin array of 16 selected lectins was used to define glycan structures showing changes between the two groups of samples. Samples were then analyzed by exactag labeling, lectin extraction and LC-MS/MS. Complement C3, ceruloplasmin, histidine rich glycoprotein (HRG), CD14 and hepatocyte growth factor (HGF), as validated by western blot, were considered putative biomarkers in differentiating early HCC from cirrhosis with a sensitivity of $72 \%$ and a specificity of $79 \%$.

\subsubsection{Liver Cancer Biomarker Proteins Involved in Inflam-} matory Processes. Paradis et al. [56] studied by SELDI-TOF eighty-two sera from patients with cirrhosis, either without (38 samples) or with (44 samples) HCC. Thirty protein peaks significantly differentiated cirrhotic patients affected by HCC from those unaffected. An algorithm showing the six highest scoring peaks allowed the correct classification of patients with or without HCC in $92 \%$ of individuals in the test set and in $90 \%$ in the validation set. After sera fractionation (IMAC-Zn spin column), analysis on NP20 chip array and protein recovery from tricine SDS-PAGE, tandem MS was performed and the highest discriminating peak $(8.9 \mathrm{kDa})$ was described as the C-terminal part of the V10 fragment of vitronectin, a protein involved in cell adhesion, humoral defense mechanism as well as cell invasion. SELDI-TOF was used to identify differentially expressed proteins in hepatocarcinoma (55 samples in total, $31 \mathrm{HBV}$-related and $24 \mathrm{HCV}$-related) and chronic hepatitis patients ( $18 \mathrm{HBV}$ and $30 \mathrm{HCV})$. After serum fractionation by anionic exchange chromatography, the proteins were characterized by 2 -DE separation and LC-MS/MS analysis. The protein complement C3a (about $8.9 \mathrm{kDa}$ ), elevated both in chronic HCV and HCV-related HCC patients, was identified as a candidate biomarker and further validated by PS20 chip immunoassay and western blot [57]. Yang et al. [58] used 2-DE combined to nano-HPLC-ESI-MS/MS to identify 14 proteins differentially expressed (12 up and 2 downregulated) in HCC patients with respect to normal controls. On the other hand, using whole serum trypsin-digested and then analyzed with nano-HPLC-ESI-MS/MS, twentynine proteins were identified with high levels of confidence. Six of them (Annexin VI isoform, Complement component 9, Ceruloplasmin-ferroxidase-, Serum amyloid A4, Serum amyloid A2, Serum amyloid A1 isoform 2), playing a role in immune and acute phase response or in membrane dynamics along endocytosis or exocytosis pathways (Annexin VI), were detected only in HCC patients. An 11 peak algorithm, generated by SELDI/TOF analysis, distinguished patients with HCC (41 samples) from those with hepatitis $C$ cirrhosis (51 samples) better than the currently used biomarkers AFP, 
AFP L3 (Lens culinaris agglutinin-reactive AFP) and PIVKAII (prothrombin induced by vitamin $\mathrm{K}$ absence-II). Within the 11-protein signature, the $13.4 \mathrm{kDa}$ feature was purified, identified as cystatin $\mathrm{C}$ by MS/MS analysis and further validated by ELISA. The cystatin C, a cysteine protease inhibitor marker of inflammation as well as renal function, resulted overexpressed in HCC samples and was described as a marker to distinguish HCC from HCV-related cirrhosis patients [59]. He et al. [60] performed by SELDI-TOF serum profiling on 81 patients with HBV-related HCC and 33 normal controls, randomly split into a training and a testing set. Six proteomic peaks $(m / z 3157.33$, 4177.02, 4284.79, $4300.80,7789.87,7984.14$ ) were considered to construct the best classification tree (sensitivity $95 \%$, specificity $100 \%$ in the testing set). Protein fraction corresponding to the $7489 \mathrm{~m} / z$ peak was isolated and characterized by MS/MS analysis as the inflammatory cytokine neutrophil activating peptide 2 (NAP-2). NAP-2 was validated by immunohistochemistry in HCC tissues and resulted specifically associated to hepatitis B-related HCC [60]. Sera from eighty-one patients with HBVrelated HCC and 80 healthy controls were divided in two sets and analyzed by SELDI-TOF. Candidate biomarkers were purified and identified by MS/MS and database searching. Two proteins, the thrombin light chain $(m / z$ 4096) and the chemokine growth-related oncogene alpha (GRO-alpha) $(\mathrm{m} / z$ 7860) were selected as putative biomarkers. A clinical validation set composed by 48 HCC, 54 liver cirrhosis, 151 patients with other cancers and 42 healthy donors was analyzed to confirm data by SELDI-immunoassay. The proteins, when associated to AFP, resulted in a sensitivity of $91.7 \%$ and a specificity of $92.7 \%$ [61]. Sera from cirrhosis and HCC patients were analyzed by cleavable stable isotope labeling (cICAT) coupled to LC-ESI-MS/MS. Among 31 proteins differentially expressed, the alpha-1 acid glycoprotein (AGP), an acute phase reactant, was chosen for western blot assay and validation in a separate study. AGP was useful for discrimination of HCC from cirrhosis in patients with AFP less than $500 \mathrm{ng} / \mathrm{mL}$ [62]. A study based on 2D-gel electrophoresis and MALDI-TOF in patients with hepatocarcinoma or liver cirrhosis revealed five proteins differentially expressed (haptoglobin, Hp2, preprohaptoglobin, SP40 and SAA1). Western blot analysis showed haptoglobin, the most representative protein, as overexpressed in HCC patients. When used in association to AFP, the molecule improved the diagnostic accuracy. Serum haptoglobin also showed diagnostic potential in AFP-negative patients [63]. Several peptides in the serum low molecular weight fraction were identified by MALDI and then characterized by LC-MS/MS. Differentially expressed peptides were described as truncations of $\mathrm{N}$ terminus of complement C3f, a fibrinopeptide, complement $\mathrm{C} 4$ alpha peptides, a zyxin peptide, a coagulation factor XIII peptide, and a biliverdin diglucuronide [64].

3.2.4. Liver Cancer Biomarker Proteins Involved in Other Functions. Feng et al. [65] used a strategy based on sonication, albumin and immunoglobulin depletion, 2-DE and MALDITOF MS/MS to analyze 20 sera, respectively, from HCC, hepatitis B (HBV) patients and normal subjects. The same number of additional sera from corresponding groups was used for the validation test. Height proteins, involved in inflammatory processes or classified as acute phase reactants (alpha-1 antitrypsin, clusterin, ceruloplasmin, haptoglobin alpha2 chain, transferrin, and transthyretin) as well as alfa-fetoprotein and the heat-shock protein 27, a stressinducible protein acting in thermotolerance, cell proliferation, and apoptosis, were differentially expressed in the above-mentioned groups. Validation by western blot analysis revealed HSP27 expressed in 90\% of $\mathrm{HCC}$, in $10 \%$ of $\mathrm{HBV}$ and in none of normal sera. Wu et al. [66] compared by 2-DE and mass spectrometry sera from HCC patients and normal controls. Eight protein spots differentially expressed were analyzed and four proteins were identified as putative biomarkers (MYH2 protein, mitochondrial ATP synthase, sulphated glycoprotein-2-clusterin SGP-2-, and glial fibrillary acidic protein (GFAP). SGP-2, known to be involved in inflammation and in the regulation of cellular proliferation, was also confirmed by immunoblotting in an independent set of samples.

3.3. Serum Biomarkers in Lung Cancer. Lung cancer is one of the leading causes of cancer-related mortality worldwide and is responsible for 1.3 million deaths worldwide annually $[104,105]$. The poor prognosis is evidenced by the 5-year survival rate which is less than $15 \%$ [106]. Lung cancers are grouped into small-cell lung cancer (SCLC) and nonsmall-cell lung cancer (NSCLC), consisting of adenocarcinomas, squamous cell carcinomas, and large-cell carcinomas [107, 108]. NSCLCs comprise approximately $80 \%$ of all lung cancers [50], with adenocarcinomas and squamous cell lung cancers each accounting for approximately $30 \%$. Many serologic biomarkers of lung cancer have emerged recently: these include carcinoembryonic antigen (CEA), the cytokeratin 19 fragment CYFRA21-1, cancer antigen CA-125 [109], plasma kallikrein [110], progastrin-releasing peptide (ProGRP), and neuron-specific enolase (NSE) [111].

3.3.1. Proteomic Patterns for Lung Cancer Detection. In a study on 208 sera (158 lung cancer, 50 healthy controls), Yang et al. [112] identified a 5 proteins peak pattern (11493, $6429,8245,5335,2538 \mathrm{Da})$ which, in a blind test, achieved sensitivity of $86.9 \%$ (79\% for stage I/II lung cancers), specificity of $80 \%$ and positive predictive value of $92.4 \%$. In particular, the pattern sensitivity was $91.4 \%$ in the detection of NSCLC. In a group of sera (54 SCLC, 24 NSCLC, 32 pneumonia patients, and 40 healthy subjects), SELDI-TOF spectra data analyzed by support vector machine (SVM) gave three patterns able to distinguish SCLC from pneumonia, NSCLC patients and from healthy individuals better than neuron specific enolase (NSE). The sensitivity and specificity ranged from $88 \%$ to $83 \%$ and from $91 \%$ to $75 \%$, respectively [113]. A 17 MS protein signature was identified in a study on 139 lung cancer patients (stage III-IV), 158 healthy individuals and then validated in two sets of 126 (63 lung cancer stage III-IV, 63 controls) and 50 (25 lung cancer stage I-II, 25 controls) individuals. The signature distinguished lung cancer patients from normal subjects and showed sensitivity and specificity of $87.3 \%$ and $81.9 \%$ in the first validation set, and $90 \%$ and $67 \%$ in the second one [114]. Du et al. [115] 
captured and concentrated serum peptides by using magnetic beads-based weak cation exchange on the ClinProt robotic platform. The peptides were analyzed by MALDI-TOF. A 5 protein fingerprint distinguished SCLC patients (30 samples) from healthy individuals (44 samples) with a specificity of $97 \%$ and a sensitivity of $90 \%$. In particular, $89 \%$ of stage I/II SCLC were correctly diagnosed.

3.3.2. Glycoproteomics in Lung Cancer. Glycoproteomic approaches have been applied to identify biomarkers for NSCLC early diagnosis. After immunoaffinity depletion of highly abundant serum proteins, glycoproteins were captured and enriched by hydrazide chemistry, recovered and then analyzed by LC-MS/MS. Thirty-eight glycopeptides from 22 proteins distinguished cases from controls. Three of these proteins (alpha-1-antichymotrypsin ACT, insulinlike growth factor-binding protein 3 IGFBP3, lipocalin-type prostaglandin D synthase L-PGDS) were verified by ELISA, showing correlation with MS results [116].

3.3.3. Lung Cancer Biomarker Proteins Involved in Inflammatory Processes. Howard et al. [71] identified by MALDITOF a peak $(m / z 11702)$ differentially expressed in lung cancer patients ( 24 subjects) with respect to individuals with no evidence of cancer (17 subjects). After purification and peptide mapping, the peak was described as the acute phase reactant serum amyloid protein $\mathrm{A}$ and further validated by ELISA. Bharti et al. [77] analyzed by MALDI-TOF differentially expressed albumin-depleted serum proteins from SCLC patients and controls, recovered from a silver-stained SDS-PAGE. The peptides were characterized by sequencing. Haptoglobin $\alpha$-subunit, validated by immunoblot, was considered as a biomarker with its level correlating with the disease stage. In addition, they analyzed by ELISA the levels of hepatocyte growth factor (HGF), a multifunctional protein which regulates both cell growth and motility, and described it as a potential SCLC biomarker. A study performed on 218 sera from 175 lung cancer patients and 43 controls by SELDITOF showed an $11.6 \mathrm{kDa}$ protein peak significantly elevated in cancer sera and increased in association to the clinical stage. Serum amyloid A protein was identified by tricine SDS-PAGE and MALDI-MS/MS analysis as a biomarker to discriminate lung cancer patients from healthy individuals. The marker was validated by immunoprecipitation and ELISA in the same samples and showed sensitivity of $84 \%$ and specificity of $80 \%$ [72]. In a study on 227 sera (146 lung cancer, 41 benign lung disease, 40 normal subjects) three peaks differentially expressed $(m / z \quad 13780,13900$, 14070) were identified by SELDI. The peaks corresponded to native transthyretin (negative acute-phase reactant) and its two variant, as demonstrated by SDS-PAGE and ESIMS/MS analysis and further validated by immunoprecipitation and immunoblotting. The transthyretin expression was significantly lower in lung cancer sera compared with sera from normal individuals, but higher compared with those obtained from benign lung disease. Subsequent ELISA assay indicated that the levels of transthyretin were consistent with those obtained by SELDI, showing approximately 65-75\% sensitivity and specificity [78]. The diagnostic accuracy of
MALDI in analyzing unfractionated serum was assessed in a study by Yildiz et al. [117] performed on 142 sera form lung cancer patients matched with 146 samples from normal controls. Samples were split into training and test set. A serum proteomic signature of seven features achieved an overall accuracy of $78 \%$ and $72.6 \%$ in the training and blinded test set, respectively. The peptides around $11500 \mathrm{Da}$ were further analyzed by using SDS-PAGE separation and LCMS/MS and described as a cluster of truncated forms of serum amyloid A protein. In a study on 154 sera from pretreated patients (55\% early, 45\% advanced-stage) an isoform of serum amyloid A, corresponding to an $11.6 \mathrm{kDa}$ SELDI peak and characterized by SDS-PAGE and tandem MS, was found to be elevated in patients with poor prognosis. In this study, sera were prefractionated in six protein fractions on the basis of their isoelectric points [73]. Forty-nine proteins were found to be differentially expressed by LC-ESI-MS/MS in pools of sera from nonsmall cell lung cancer (adenocarcinoma and squamous cell carcinoma) with respect to healthy controls. Multiple reaction monitoring (MRM) assay was used to confirm the abundance of four selected proteins (serum amyloid A-SSA-, alpha-1 acid glycoproteins 1 and 2-AAG 1 and 2-, clusterin-CLU-). SSA and AAG 1 and 2 showed higher spectral count in lung cancer serum pool [74]. Analysis by SELDI-TOF of 227 sera showed 5 peaks $(\mathrm{m} / z$ 11530, 11700, 13780, 13900, 14070) identifying native serum amyloid A protein and transthyretin, and some of their variants as lung cancer biomarkers [75]. Serum amyloid A1 and A2 proteins were identified by LC-ESI-MS/MS in lung cancer pooled sera after SDS-PAGE fractionation. The levels were higher in lung cancer patients with respect both to patients affected by other pulmonary diseases or different cancers and to healthy controls. The results were confirmed by ELISA. Moreover, SSA expression in lung cancer samples was detected by tissue-microarray analysis [76].

3.3.4. Lung Cancer Biomarker Proteins Involved in Other Functions. Ueda et al. [79] described a method based on enrichment of the peptidomic fraction and analysis by nanoLC-MS/MS. After further characterization by MRM-based relative quantification, peptides from apolipoprotein A4 (APOA4), fibrinogen alpha chain (FIBA), and limbin (LBN), a positive regulator of the hedgehog signaling pathway, have been identified as useful biomarkers for early detection and staging of lung tumors.

3.4. Serum Biomarkers in Pancreatic Cancer. Pancreatic cancer is the fourth leading cause of cancer death in both men and women. The high mortality associated with it can be essentially attributed to advanced stage of disease at patient presentation. Few patients with pancreatic cancer are cured without surgical resection. The overall 5-year survival is about $5 \%$, and only $20 \%$ of patients are candidates for surgical resection and possible treatment. For this small percentage of patients undergoing resection, even when followed by multimodal therapy, 5-year survival rates are still less than 25\% [118-120]. Current methods for diagnosing pancreatic cancer are relatively ineffective to identify small potentially curable lesions. The marker recommended in clinical practice 
is serum CA-19-9. However, this marker is of little utility in establishing early diagnosis [121]. To date, there are no efficient modalities to early detect pancreatic cancer and strategies to improve survival have focused just on chemotherapy in the neoadjuvant setting or after resection.

3.4.1. Proteomic Patterns for Pancreatic Cancer Detection. In a study on 15 healthy controls, 24 cancer and 11 chronic pancreatitis patients prospectively collected, the low molecular serum fraction was enriched and analyzed by MALDITOF. An eight peaks serum signature $(\mathrm{m} / z$ 4470, 4792, 8668, $8704,8838,9194,9713,15958)$ differentiated cancer patients from normal individuals (sensitivity and specificity of $88 \%$ and $93 \%$ ), cancer from pancreatitis patients (sensitivity and specificity of $88 \%$ and $30 \%$ ), and cancer from healthy plus pancreatitis-affected individuals (sensitivity and specificity of $88 \%$ and $66 \%$ ). The most significant peak, $\mathrm{m} / z$ 9713, was described by MS/MS analysis as the apolipoprotein CIII [82]. Liu et al. [122] used SELDI-TOF technology to differentiate cancer from different pancreatic conditions, by studying 118 serum samples, split in training and test set. Two MS patterns, differentiating pancreatic adenocarcinoma from healthy controls and chronic pancreatitis, yielded in the test set sensitivity and specificity of $91.6 \%$ (cancer versus controls) and sensitivity of $90.9 \%$, specificity of $80 \%$ (cancer versus chronic pancreatitis).

3.4.2. Pancreatic Cancer Biomarker Proteins Involved in Inflammatory Processes. An orthotopic nude mouse model of human pancreatic cancer was used to detect serum biomarkers [83]. Mice were injected with a human pancreatic cancer cell line and then were divided in groups treated with anti-cancer drugs for some weeks. Sera were recovered and analyzed by SELDI Proteinchip technology. Plasma from 135 pancreatic cancer patients and 113 healthy individuals were at the same time examined. An $11.7 \mathrm{kDa}$ protein peak, correlating with tumor weight, was detected in mice sera. After purification and separation by SDSPAGE, the corresponding protein was identified as serum amyloid protein A and confirmed by western blotting. The level of SAA detected in plasma of pancreatic cancer patients correlated with the clinical stage. Ninety-six sera from pancreatic cancer patients undergoing surgery were fractionated by chromatography and analyzed by SELDI in comparison with as many sera from healthy controls. Twenty-four differentially expressed peaks were identified. Twenty-one of them resulted in downregulated pancreatic cancer samples. After purification, several proteins were identified by peptide mapping and postsource decay-matrix-assisted laser desorption ionization-TOF-MS. Down-regulated apolipoprotein AII, transthyretin, and apolipoprotein A-I were described as potential markers in pancreatic cancer [84]. Hanas et al. [85] studied sera from pancreatic cancer patients by gel electrophoresis in order to highlight protein bands differing quantitatively. The proteins were analyzed and characterized by ESI ion-trap tandem MS. Three high mass proteins ( $\alpha$-2 macroglobulin, ceruloplasmin, complement 3C) were elevated in cancer sera with respect to controls. The ESIMS analysis revealed great heterogeneity especially in the low mass region. By statistical analysis, twenty low-mass serum peaks correlating to controls and 20 different peaks correlating to cancer sera were found. A study performed by Fiedler et al. [86] on forty sera from patients matched with forty samples from healthy controls was focused on MALDITOF peptidome profile analysis after using magnetic beads for protein fractionation. Data were validated by using an additional 20 plus 20 sera set. Two significant peaks $(\mathrm{m} / \mathrm{z}$ 3884 and 5959 ) showed $86.3 \%$ sensitivity and $97.6 \%$ specificity for discriminating patients from controls. The 3884 peak was described and further validated by immunoassay as platelet factor 4 (PF4). PF4, used in combination with CA-19-9, significantly improved sensitivity and specificity for the identification of pancreatic cancer [86]. Rong et al. [87] used immunoaffinity depletion of highly abundant proteins and 2-DE to identify 16 protein spots differentially expressed (8 iper- and 8 ipoexpressed in cancer sera). The proteins were analyzed and sequenced. Mannose-binding lectin 2 and myosin light chain kinase 2, a serine/threonine kinase, were identified as potential biomarkers for the pancreatic cancer diagnosis and further validated by western blot in an independent set of sera from pancreatic cancer patients and normal controls. Low molecular weight $(<60 \mathrm{kDa})$ serum proteome from a training set composed by 24 patients with pancreatic cancer and 21 controls was analyzed by HPLCESI-MS/MS. Among many peaks identified, a peptide from CXC chemokine ligand 7 (CXCL7) was significantly reduced in cancer sera. Data were confirmed by high-density protein microarray in a large cohort of 140 patients affected by pancreatic cancer, 10 patients with chronic pancreatitis and 87 healthy controls. Combination of CXCL7 and CA-19-9, improved the discriminatory power for pancreatic cancer [88]. In order to limit the complexity of the plasma proteome, Pan et al. [89] employed multidimensional fractionation followed by HPLC-MS/MS. Many proteins/peptides were identified with this method. A group of differentially expressed proteins was selected and evaluated on a separate cohort of samples from pancreatic cancer, chronic pancreatitis patients, and nonpancreatic disease control. A composite marker of the tissue inhibitor of metalloproteinases TIMP1 and the adhesion molecule ICAM1, as characterized by ELISA, showed significant better performance than CA19-9 in distinguishing pancreatic cancer, pancreatitis, nonpancreatic diseases and healthy controls. Forty-five samples from patients affected by pancreatic cancer and 20 from healthy controls were analyzed by $2-\mathrm{DE}$ and LC-MS/MS. Seven protein spots were differentially expressed. Serum isoforms of alpha-1-antitrypsin (AAT), also confirmed by western blot, were described as upregulated and potential serum biomarkers for pancreatic cancer [90].

3.4.3. Pancreatic Cancer Protein Biomarkers Involved in Other Functions. Bloomston et al. [91] analyzed by highresolution 2-DE thirty preoperative sera from pancreatic cancer and thirty-two from healthy individuals. Differentially expressed spots were recovered and analyzed by MALDITOF and LC-MS/MS. Approximately 150 proteins resulted commonly overexpressed in all cancer patients. Four proteins discriminated $100 \%$ of pancreatic cancer and $94 \%$ of normal 
samples. Among them, fibrinogen- $\gamma$ was identified as putative biomarker and further validated by enzymatic analysis in sera and immunohistochemistry in tumor tissues. One hundred and twenty-six sera form pancreatic cancer patients (84 with diabetes) were examined by SELDI-TOF in comparison to 61 sera from chronic pancreatitis (32 with diabetes), 24 from type 2 diabetes mellitus patients, and 12 from healthy controls. Classification algorithms obtained by MS analysis resulted to improve the diagnostic accuracy of CA-19-9 in pancreatic cancer diagnosis and to facilitate the differential diagnosis between pancreatic cancer and type 2 diabetes mellitus. Among the large number of peptides, that described with the $m / z 3519$ was identified as a member of the EGF-like family [123]. Fifty-eight sera from patients with pancreatic cancer were compared with 18 samples from patients affected by benign disease and 51 healthy controls. Sera were analyzed using a strong anionic exchange chromatography proteinchip and SELDI-TOF. Sixty-one protein peaks were detected to construct multiple classification trees to distinguish the disease groups, reaching $83 \%$ sensitivity and almost $100 \%$ specificity in discriminating cancer from controls and benign disease. Putative protein biomarkers were identified: one $(\mathrm{m} / z$ 4016) showed a downregulated trend in preoperative versus post-operative sera, three $(m / z 4155,4791,28068)$ were detected in the differential diagnosis of the 3 test groups. C14orf166, a protein involved in modulation of mRNA transcription by Polymerase II, was identified as corresponding to the 28068 peak by ProteinChip immunoassay. The molecule showed levels significantly higher in pancreatic cancer patients, as confirmed by immunoenzymatic methods. C14orf166 was also iper-expressed in tumor cells [92]. A SELDI-TOF protein panel derived from the study of a training set composed by 38 pancreatic cancer sera, 54 disease controls, and 68 healthy volunteers was further validated on a first validation set (40 pancreatic cancer, 21 disease controls, 19 healthy volunteers) and then, by ELISA, on a second one (33 pancreatic cancer, 28 disease controls, 18 healthy volunteers). Some proteins corresponding to peaks of interest were purified and identified. A simplified diagnostic panel comprising CA-19-9, apolipoprotein C-I, apolipoprotein AII, additionally validated by ELISA on the second validation set, resulted to improve the diagnostic ability of CA-19-9 [124]. Potential prognostic markers were initially identified by nano-LC-MS/MS in 4 groups of sera, each from 10 patients, selected on the basis of survival (long or short) and therapy (gemcitabine plus bevacizumab, or gemcitabine plus placebo). Alpha1-antichymotrypsin (AACT) was negatively correlated with overall survival and considered as a prognostic marker for pancreatic cancer [93].

\section{Conclusions}

Cancer is one of the leading causes of death worldwide. Advances in screening methods significantly improved early diagnosis with consequent enhancement of prognosis, survival and treatment efficacy. Unfortunately, some tumors are difficult to diagnose before the disease is in advanced or metastasizing state. Therefore, there is an urgent need to discover novel biomarkers which provide sensitive and specific disease detection. Over the past decade, serum biomarkers have been identified in sera from cancer patients by using powerful high-throughput technologies. Mass spectrometry allowed the identification of hundreds of proteins within complex biological samples such as tissues, serum, plasma, and urine. MS analytical attributes in biomarker discovery are its high mass accuracy, resolution and ability to characterize the peptides at the level of their aminoacidic sequence. Several workflows including methods for serum samples preparation (e.g., high abundance protein removal, serum fractionation), SDS-PAGE and 2D-GE, LC, different MS platforms, and protein chip arrays have been used for biomarker discovery. Many differential MS peak profiles were identified and several proteins were characterized and described as potential biomarkers for high mortality tumors (Tables 1-4), achieving different levels of sensitivity and specificity to diagnose the disease. Many of these proteins are involved in fundamental processes such as inflammation, cellular differentiation and proliferation, and apoptosis. Among them, positive (i.e., serum amyloid A, ceruloplasmin, complement factors, haptoglobin) and negative acute-phase reactants (i.e., transthyretin, transferrin) were differentially expressed in sera from ovary, lung, liver, and pancreatic cancer patients. Some putative ovarian cancer biomarkers described in this paper, such as the keratin $2 \mathrm{a}$, the glycosyltransferase-like $1 \mathrm{~B}$, involved in glycosylation processes, and the casein kinase alpha 1 , a serine/threonine kinase involved in cellular differentiation, proliferation and apoptosis, have been associated with processes related to cancer [125-128]. Similarly, the mannose binding lectin 2 (MBL2), a mediator of inflammation which results iperexpressed in pancreatic cancer sera, is involved in cancer processes. Genetic alterations of MBL2 can increase colon cancer susceptibility in African Americans and a MBL genetic polymorphism, associated to a reduction of vaginal MBL concentration, may be a risk for development of ovarian cancer $[129,130]$. The chemokine CCL18, here described as candidate ovarian cancer serum biomarker, was also considered as a urine biomarker for bladder cancer detection [131]. Likewise, the HCC biomarker cystatin C, an inhibitor of cystein proteinases, showed significantly higher levels also in sera from lung cancer patients [132], and the HCC and lung cancer putative biomarker alpha-1 acid glycoprotein 1, an acute phase protein, was found as well elevated in sera and tumor tissues from patients affected by gastric carcinoma [133]. The here described liver cancer biomarker heat shock protein 27, a protein with cytoprotective and anti-apoptotic activity, measured by immunoenzymatic assay, was confirmed to be elevated in an independent cohort of sera from HCC patients [134].

Despite the great advances in the application of MS in serum biomarker discovery, several challenges remain. The identification of differential serum protein profiles and specific molecules able to discriminate normal from diseased subjects requires a technology able to highlight small differences and to process large series of serum samples. Although MS is the most powerful approach for biomarker identification, there are some boundaries in the analysis of serum. These can be attributable to the complex nature of serum and its tremendous dynamic range, to diurnal 
variation in protein expression, instability of proteins due to in vivo or ex vivo protease activity, pre-analytical methods reproducibility as well as to the intrinsic MS sensitivity (> $\mu \mathrm{g} / \mathrm{mL}$ ) [135] in detecting analytes which usually range between $50 \mathrm{pg} / \mathrm{mL}$ and $10 \mathrm{ng} / \mathrm{mL}$ [136]. Accurate selection of cases and controls, standardization of sample collection and storage conditions, utilization of adequate and effective methods focused on reducing the complexity of serum/plasma prior MS analysis, use of different protein array with complementary binding conditions, refined bioinformatic and statistical analysis to process data, and suitable validation workflows by immunoassay on larger sets of independent samples are necessary elements to circumvent criticisms and improve the biomarker discovery process.

\section{Acknowledgments}

This work was supported in part by MIUR FIRB Grant to E. Alesse, by the "Associazione Italiana per la RicercasulCancro" (AIRC) Grant to F. Zazzeroni, and by MIUR PRIN Grant to F. Zazzeroni.

\section{References}

[1] A. M. Glas, A. Floore, L. J. M. J. Delahaye et al., "Converting a breast cancer microarray signature into a high-throughput diagnostic test," BMC Genomics, vol. 7, article 278, 2006.

[2] M. E. Straver, A. M. Glas, J. Hannemann et al., "The 70-gene signature as a response predictor for neoadjuvant chemotherapy in breast cancer," Breast Cancer Research and Treatment, vol. 119, no. 3, pp. 551-558, 2010.

[3] S. Mook, M. Knauer, J. M. Bueno-De-Mesquita et al., "Metastatic potential of T1 breast cancer can be predicted by the 70-gene MammaPrint signature," Annals of Surgical Oncology, vol. 17, no. 5, pp. 1406-1413, 2010.

[4] M. Zhou and T. D. Veenstra, "Mass spectrometry: $\mathrm{m} / \mathrm{z}$ 1983-2008," BioTechniques, vol. 44, no. 5, pp. 667-670, 2008.

[5] F. E. Ahmed, "Utility of mass spectrometry for proteome analysis-part I: conceptual and experimental approaches," Expert Review of Proteomics, vol. 5, no. 6, pp. 841-864, 2008.

[6] E. P. Diamandis, "Mass spectrometry as a diagnostic and a cancer biomarker discovery tool: opportunities and potential limitations," Molecular and Cellular Proteomics, vol. 3, no. 4, pp. 367-378, 2004.

[7] E. F. Petricoin, C. Belluco, R. P. Araujo, and L. A. Liotta, “The blood peptidome: a higher dimension of information content for cancer biomarker discovery," Nature Reviews Cancer, vol. 6, no. 12, pp. 961-967, 2006.

[8] M. De Bock, D. de Seny, M. A. Meuwis et al., "Challenges for biomarker discovery in body fluids using SELDI-TOF-MS," Journal of Biomedicine \& Biotechnology, vol. 2010, Article ID 906082, 15 pages, 2010.

[9] J. M. Jacobs, J. N. Adkins, W. J. Qian et al., "Utilizing human blood plasma for proteomic biomarker discovery," Journal of Proteome Research, vol. 4, no. 4, pp. 1073-1085, 2005.

[10] N. L. Anderson, M. Polanski, R. Pieper et al., "The human plasma proteome: a non redundant list developed by combination of four separate sources," Molecular and Cellular Proteomics, vol. 3, no. 4, pp. 311-326, 2004.
[11] Y. Shen, J. Kim, E. F. Strittmatter et al., "Characterization of the human blood plasma proteome," Proteomics, vol. 5, no. 15, pp. 4034-4045, 2005.

[12] L. A. Liotta and E. F. Petricoin, "Serum peptidome for cancer detection: spinning biologic trash into diagnostic gold," Journal of Clinical Investigation, vol. 116, no. 1, pp. 26-30, 2006.

[13] R. J. Leatherbarrow and P. D. Dean, "Studies on the mechanism of binding of serum albumins to immobilized cibacron blue F3G A," Biochemical Journal, vol. 189, no. 1, pp. 27-34, 1980.

[14] F. Di Girolamo, P. G. Righetti, A. D’Amato, and M. C. Chung, "Cibacron Blue and proteomics: the mystery of the platoon missing in action," Journal of Proteomics, vol. 74, no. 12, pp. 2856-2865, 2011.

[15] N. Seam, D. A. Gonzales, S. J. Kern, G. L. Hortin, G. T. Hoehn, and A. F. Suffredini, "Quality control of serum albumin depletion for proteomic analysis," Clinical Chemistry, vol. 53, no. 11, pp. 1915-1920, 2007.

[16] K. Björhall, T. Miliotis, and P. Davidsson, "Comparison of different depletion strategies for improved resolution in proteomic analysis of human serum samples," Proteomics, vol. 5, no. 1, pp. 307-317, 2005.

[17] L. Guerrier, F. Fortis, and E. Boschetti, "Solid-phase fractionation strategies applied to proteomics investigations," Methods in Molecular Biology, vol. 818, pp. 11-33, 2011.

[18] L. Guerrier, L. Lomas, and E. Boschetti, "A simplified monobuffer multidimensional chromatography for high-throughput proteome fractionation," Journal of Chromatography A, vol. 1073, no. 1-2, pp. 25-33, 2005.

[19] E. Orvisky, S. K. Drake, B. M. Martin et al., "Enrichment of low molecular weight fraction of serum for MS analysis of peptides associated with hepatocellular carcinoma," Proteomics, vol. 6, no. 9, pp. 2895-2902, 2006.

[20] S. Camerini, M. L. Polci, L. A. Liotta, E. F. Petricoin, and W. Zhou, "A method for the selective isolation and enrichment of carrier protein-bound low-molecular weight proteins and peptides in the blood," Proteomics-Clinical Applications, vol. 1, no. 2, pp. 176-184, 2007.

[21] A. J. VanMeter, S. Camerini, M. L. Polci et al., "Serum lowmolecular-weight protein fractionation for biomarker discovery," Methods in Molecular Biology, vol. 823, pp. 237-249, 2012.

[22] A. Luchini, D. H. Geho, B. Bishops et al., "Smart hydrogel particles: biomarker harvesting: one-step affinity purification, size exclusion, and protection against degradation," Nano Letters, vol. 8, no. 1, pp. 350-361, 2008.

[23] A. Luchini, C. Longo, V. Espina, E. F. Petricoin III, and L. A. Liotta, "Nanoparticle technology: addressing the fundamental roadblocks to protein biomarker discovery," Journal of Materials Chemistry, vol. 19, no. 29, pp. 5071-5077, 2009.

[24] C. Longo, A. Patanarut, T. George et al., "Core-shell hydrogel particles harvest, concentrate and preserve labile low abundance biomarkers," PLoS One, vol. 4, no. 3, article e4763, 2009.

[25] D. Tamburro, C. Fredolini, V. Espina et al., "Multifunctional core-shell nanoparticles: discovery of previously invisible biomarkers," Journal of the American Chemical Society, vol. 133, no. 47, pp. 19178-19188, 2011.

[26] H. Zhang, X. J. Li, D. B. Martin, and R. Aebersold, "Identification and quantification of N-linked glycoproteins using hydrazide chemistry, stable isotope labeling and mass spectrometry," Nature Biotechnology, vol. 21, no. 6, pp. 660-666, 2003. 
[27] R. Apweiler, H. Hermjakob, and N. Sharon, "On the frequency of protein glycosylation, as deduced from analysis of the SWISSPROT database," Biochimica et Biophysica Acta, vol. 1473, no. 1, pp. 4-8, 1999.

[28] L. Tong, G. Baskaran, M. B. Jones, J. K. Rhee, and K. J. Yarema, "Glycosylation changes as markers for the diagnosis and treatment of human disease," Biotechnology and Genetic Engineering Reviews, vol. 20, pp. 199-244, 2003.

[29] Y. Tian, Y. Zhou, S. Elliott, R. Aebersold, and H. Zhang, "Solidphase extraction of N-linked glycopeptides," Nature Protocols, vol. 2, no. 2, pp. 334-339, 2007.

[30] B. Sun, J. A. Ranish, A. G. Utleg et al., "Shotgun glycopeptide capture approach coupled with mass spectrometry for comprehensive glycoproteomics," Molecular and Cellular Proteomics, vol. 6, no. 1, pp. 141-149, 2007.

[31] H. Kaji, H. Saito, Y. Yamauchi et al., "Lectin affinity capture, isotope-coded tagging and mass spectrometry to identify $\mathrm{N}$ linked glycoproteins," Nature Biotechnology, vol. 21, no. 6, pp. 667-672, 2003.

[32] R. Aebersold and M. Mann, "Mass spectrometry-based proteomics," Nature, vol. 422, no. 6928, pp. 198-207, 2003.

[33] J. R. Yates III, "Mass spectral analysis in proteomics," Annual Review of Biophysics and Biomolecular Structure, vol. 33, pp. 297-316, 2004.

[34] F. Hillenkamp, M. Karas, R. C. Beavis, and B. T. Chait, "Matrix-assisted laser desorption/ionization mass spectrometry of biopolymers," Analytical Chemistry, vol. 63, no. 24, pp. 1193A-1203A, 1991.

[35] Y. Qu, B. L. Adam, Y. Yasui et al., "Boosted decision tree analysis of surface-enhanced laser desorption/ionization mass spectral serum profiles discriminates prostate cancer from noncancer patients," Clinical Chemistry, vol. 48, no. 10, pp. 1835-1843, 2002.

[36] Z. Zhang, R. C. Bast Jr., Y. Yu et al., “Three biomarkers identified from serum proteomic analysis for the detection of early stage ovarian cancer," Cancer Research, vol. 64, no. 16, pp. 5882-5890, 2004.

[37] T. W. Hutchens and T. T. Yip, "New desorption strategies for the mass-spectrometric analysis of macromolecules," Rapid Communications in Mass Spectrometry, vol. 7, pp. 576-580, 1993.

[38] N. Tang, P. Tornatore, and S. R. Weinberger, "Current developments in SELDI affinity technology," Mass Spectrometry Reviews, vol. 23, no. 1, pp. 34-44, 2004.

[39] J. B. Fenn, M. Mann, C. K. Meng, S. F. Wong, and C. M. Whitehouse, "Electrospray ionization for mass spectrometry of large biomolecules," Science, vol. 246, no. 4926, pp. 64-71, 1989.

[40] D. F. Hunt, J. R. Yates III, J. Shabanowitz, S. Winston, and C. R. Hauer, "Protein sequencing by tandem mass spectrometry," Proceedings of the National Academy of Sciences of the United States of America, vol. 83, no. 17, pp. 6233-6237, 1986.

[41] K. R. Kozak, F. Su, J. P. Whitelegge, K. Faull, S. Reddy, and R. Farias-Eisner, "Characterization of serum biomarkers for detection of early stage ovarian cancer," Proteomics, vol. 5, no. 17, pp. 4589-4596, 2005.

[42] B. Ye, D. W. Cramer, S. J. Skates et al., "Haptoglobin- $\alpha$ subunit as potential serum biomarker in ovarian cancer: identification and characterization using proteomic profiling and mass spectrometry," Clinical Cancer Research, vol. 9, no. 8, pp. 2904-2911, 2003.
[43] N. Ahmed, G. Barker, K. T. Oliva et al., "Proteomic-based identification of haptoglobin-1 precursor as a novel circulating biomarker of ovarian cancer," British Journal of Cancer, vol. 91, no. 1, pp. 129-140, 2004.

[44] H. R. Bergen III, G. Vasmatzis, W. A. Cliby, K. L. Johnson, A. L. Oberg, and D. C. Muddiman, "Discovery of ovarian cancer biomarkers in serum using NanoLC electrospray ionization TOF and FT-ICR mass spectrometry," Disease Markers, vol. 19, no. 4-5, pp. 239-249, 2003-2004.

[45] S. A. Moshkovskii, M. V. Serebryakova, K. B. Kuteykin-Teplyakov et al., "Ovarian cancer marker of $11.7 \mathrm{kDa}$ detected by proteomics is a serum amyloid A1," Proteomics, vol. 5, no. 14, pp. 3790-3797, 2005.

[46] A. Woong-Shick, P. Sung-Pil, B. Su-Mi et al., "Identification of hemoglobin- $\alpha$ and $-\beta$ subunits as potential serum biomarkers for the diagnosis and prognosis of ovarian cancer," Cancer Science, vol. 96, no. 3, pp. 197-201, 2005.

[47] M. F. Lopez, A. Mikulskis, S. Kuzdzal et al., "A novel, highthroughput workflow for discovery and identification of serum carrier protein-bound peptide biomarker candidates in ovarian cancer samples," Clinical Chemistry, vol. 53, no. 6, pp. 1067-1074, 2007.

[48] Q. Wang, D. Li, W. Zhang, B. Tang, Q. Q. Li, and L. Li, "Evaluation of proteomics-identified CCL18 and CXCL1 as circulating tumor markers for differential diagnosis between ovarian carcinomas and benign pelvic masses," International Journal of Biological Markers, vol. 26, no. 4, pp. 262-273, 2011.

[49] J. F. Timms, U. Menon, D. Devetyarov et al., "Early detection of ovarian cancer in samples pre-diagnosis using CA125 and MALDI-MS peaks," Cancer Genomics Proteomics, vol. 8, no. 6, pp. 289-305, 2011.

[50] A. Jemal, R. Siegel, J. Xu, and E. Ward, "Cancer statistics, 2010," CA: A Cancer Journal for Clinicians, vol. 60, no. 5, pp. 277-300, 2010.

[51] U. Menon and I. J. Jacobs, "Recent developments in ovarian cancer screening," Current Opinion in Obstetrics and Gynecology, vol. 12, no. 1, pp. 39-42, 2000.

[52] S. A. Cannistra, "Cancer of the ovary," New England Journal of Medicine, vol. 351, no. 24, pp. 2519-2565, 2004.

[53] V. Nossov, M. Amneus, F. Su et al., "The early detection of ovarian cancer: from traditional methods to proteomics. Can we really do better than serum CA-125?" American Journal of Obstetrics and Gynecology, vol. 199, no. 3, pp. 215-223, 2008.

[54] L. S. Cohen, P. F. Escobar, C. Scharm, B. Glimco, and D. A. Fishman, "Three-dimensional power doppler ultrasound improves the diagnostic accuracy for ovarian cancer prediction," Gynecologic Oncology, vol. 82, no. 1, pp. 40-48, 2001.

[55] Y. Liu, J. He, C. Li et al., "Identification and confirmation of biomarkers using an integrated platform for quantitative analysis of glycoproteins and their glycosylations," Journal of Proteome Research, vol. 9, no. 2, pp. 798-805, 2010.

[56] V. Paradis, F. Degos, D. Dargère et al., "Identification of a new marker of hepatocellular carcinoma by serum protein profiling of patients with chronic liver diseases," Hepatology, vol. 41, no. 1, pp. 40-47, 2005.

[57] I. N. Lee, C. H. Chen, J. C. Sheu et al., "Identification of complement $\mathrm{C} 3 \mathrm{a}$ as a candidate biomarker in human chronic hepatitis $\mathrm{C}$ and HCV-related hepatocellular carcinoma using a proteomics approach," Proteomics, vol. 6, no. 9, pp. 2865-2873, 2006.

[58] M. H. Yang, Y. C. Tyan, S. B. Jong, Y. F. Huang, P. C. Liao, and M. C. Wang, "Identification of human hepatocellular 
carcinoma-related proteins by proteomic approaches," Analytical and Bioanalytical Chemistry, vol. 388, no. 3, pp. 637-643, 2007.

[59] N. T. Zinkin, F. Grall, K. Bhaskar et al., "Serum proteomics and biomarkers in hepatocellular carcinoma and chronic liver disease," Clinical Cancer Research, vol. 14, no. 2, pp. 470-477, 2008.

[60] M. He, J. Qin, R. Zhai et al., "Detection and identification of NAP-2 as a biomarker in hepatitis B-related hepatocellular carcinoma by proteomic approach," Proteome Science, vol. 6, article 10, 2008.

[61] F. X. Wu, Q. Wang, Z. M. Zhang et al., "Identifying serological biomarkers of hepatocellular carcinoma using surfaceenhanced laser desorption/ionization-time-of-flight mass spectroscopy," Cancer Letters, vol. 279, no. 2, pp. 163-170, 2009.

[62] X. Kang, L. Sun, K. Guo et al., "Serum protein biomarkers screening in HCC patients with liver cirrhosis by ICAT-LCMS/MS," Journal of Cancer Research and Clinical Oncology, vol. 136, no. 8, pp. 1151-1159, 2010.

[63] H. Shu, X. Kang, K. Guo et al., "Diagnostic value of serum haptoglobin protein as hepatocellular carcinoma candidate marker complementary to $\alpha$ fetoprotein," Oncology Reports, vol. 24, no. 5, pp. 1271-1276, 2010.

[64] Y. An, S. Bekesova, N. Edwards, and R. Goldman, "Peptides in low molecular weight fraction of serum associated with hepatocellular carcinoma," Disease Markers, vol. 29, no. 1, pp. 11-20, 2010.

[65] J. T. Feng, Y. K. Liu, H. Y. Song et al., "Heat-shock protein 27: a potential biomarker for hepatocellular carcinoma identified by serum proteome analysis," Proteomics, vol. 5, no. 17, pp. 4581-4588, 2005.

[66] W. Wu, J. Li, Y. Liu, C. Zhang, X. Meng, and Z. Zhou, "Comparative proteomic studies of serum from patients with hepatocellular carcinoma," Journal of Investigative Surgery, vol. 25, no. 1, pp. 37-42, 2012.

[67] E. F. Petricoin, A. M. Ardekani, B. A. Hitt et al., "Use of proteomic patterns in serum to identify ovarian cancer," Lancet, vol. 359, no. 9306, pp. 572-577, 2002.

[68] K. R. Kozak, M. W. Amneus, S. M. Pusey et al., "Identification of biomarkers for ovarian cancer using strong anion-exchange ProteinChips: potential use in diagnosis and prognosis," Proceedings of the National Academy of Sciences of the United States of America, vol. 100, no. 21, pp. 12343-12348, 2003.

[69] H. Zhang, B. Kong, X. Qu, L. Jia, B. Deng, and Q. Yang, "Biomarker discovery for ovarian cancer using SELDI-TOF-MS," Gynecologic Oncology, vol. 102, no. 1, pp. 61-66, 2006.

[70] J. R. Hocker, E. A. Bishop, S. A. Lightfoot et al., "Serum profiling to distinguish early-and late-stage ovariancancer patients from disease-free individuals," Cancer Investigation, vol. 30, no. 2, pp. 189-197, 2012.

[71] B. A. Howard, M. Z. Wang, M. J. Campa, C. Corro, M. C. Fitzgerald, and E. F. Patz Jr., "Identification and validation of a potential lung cancer serum biomarker detected by matrixassisted laser desorption/ionization-time of flight spectra analysis," Proteomics, vol. 3, no. 9, pp. 1720-1724, 2003.

[72] S. Dai, X. Wang, L. Liu et al., "Discovery and identification of Serum Amyloid A protein elevated in lung cancer serum," Science in China, Series C, vol. 50, no. 3, pp. 305-311, 2007.

[73] W. C. S. Cho, T. T. Yip, W. W. Cheng, and J. S. K. Au, "Serum amyloid A is elevated in the serum of lung cancer patients with poor prognosis," British Journal of Cancer, vol. 102, no. 12, pp. 1731-1735, 2010.
[74] X. Zeng, B. L. Hood, T. Zhao et al., "Lung cancer serum biomarker discovery using label-free liquid chromatographytandem mass spectrometry," Journal of Thoracic Oncology, vol. 6, no. 4, pp. 725-734, 2011.

[75] L. Liu, J. Liu, Y. Wang et al., "A combined biomarker pattern improves the discrimination of lung cancer," Biomarkers, vol. 16, no. 1, pp. 20-30, 2011.

[76] H. J. Sung, J. M. Ahn, Y. H. Yoon et al., "Identification and validation of SAA as a potential lung cancer biomarker and its involvement in metastatic pathogenesis of lung cancer," Journal of Proteome Research, vol. 10, no. 3, pp. 1383-1395, 2011.

[77] A. Bharti, P. C. Ma, G. Maulik et al., "Haptoglobin $\alpha$-subunit and hepatocyte growth factor can potentially serve as serum tumor biomarkers in small cell lung cancer," Anticancer Research, vol. 24, no. 2C, pp. 1031-1038, 2004.

[78] L. Liu, J. Liu, S. Dai et al., "Reduced transthyretin expression in sera of lung cancer," Cancer Science, vol. 98, no. 10, pp. 1617-1624, 2007.

[79] K. Ueda, N. Saichi, S. Takami et al., "A comprehensive peptidome profiling technology for the identification of early detection biomarkers for lung adenocarcinoma," PLoS One, vol. 6, no. 4, article e18567, 2011.

[80] H. J. An, S. Miyamoto, K. S. Lancaster et al., "Profiling of glycans in serum for the discovery of potential biomarkers for ovarian cancer," Journal of Proteome Research, vol. 5, no. 7, pp. 1626-1635, 2006.

[81] G. S. Leiserowitz, C. Lebrilla, S. Miyamoto et al., "Glycomics analysis of serum: a potential new biomarker for ovarian cancer?" International Journal of Gynecological Cancer, vol. 18, no. 3, pp. 470-475, 2008.

[82] K. Kojima, S. Asmellash, C. A. Klug, W. E. Grizzle, J. A. Mobley, and J. D. Christein, "Applying proteomic-based biomarker tools for the accurate diagnosis of pancreatic cancer," Journal of Gastrointestinal Surgery, vol. 12, no. 10, pp. 1683-1690, 2008.

[83] K. Yokoi, L. C. Shih, R. Kobayashi et al., "Serum amyloid A as a tumor marker in sera of nude mice with orthotopic human pancreatic cancer and in plasma of patients with pancreatic cancer," International Journal of Oncology, vol. 27, no. 5, pp. 1361-1369, 2005.

[84] M. Ehmann, K. Felix, D. Hartmann et al., "Identification of potential markers for the detection of pancreatic cancer through comparative serum protein expression profiling," Pancreas, vol. 34, no. 2, pp. 205-214, 2007.

[85] J. S. Hanas, J. R. Hocker, J. Y. Cheung et al., "Biomarker identification in human pancreatic cancer sera," Pancreas, vol. 36, no. 1, pp. 61-69, 2008.

[86] G. M. Fiedler, A. B. Leichtle, J. Kase et al., "Serum peptidome profiling revealed platelet factor 4 as a potential discriminating peptide associated with pancreatic cancer," Clinical Cancer Research, vol. 15, no. 11, pp. 3812-3819, 2009.

[87] Y. Rong, D. Jin, C. Hou et al., "Proteomics analysis of serum protein profiling in pancreatic cancer patients by DIGE: upregulation of mannose-binding lectin 2 and myosin light chain kinase 2," BMC Gastroenterology, vol. 10, article 68, 2010.

[88] J. Matsubara, K. Honda, M. Ono et al., "Reduced plasma level of CXC chemokine ligand 7 in patients with pancreatic cancer," Cancer Epidemiology Biomarkers and Prevention, vol. 20, no. 1, pp. 160-171, 2011.

[89] S. Pan, R. Chen, D. A. Crispin et al., "Protein alterations associated with pancreatic cancer and chronic pancreatitis found in human plasma using global quantitative proteomics 
profiling," Journal of Proteome Research, vol. 10, no. 5, pp. 2359-2376, 2011.

[90] Y. Wang, Y. Kuramitsu, S. Yoshino et al., "Screening for serological biomarkers of pancreatic cancer by two-dimensional electrophoresis and liquid chromatography-tandem mass spectrometry," Oncology Reports, vol. 26, no. 1, pp. 287-292, 2011.

[91] M. Bloomston, J. X. Zhou, A. S. Rosemurgy, W. Frankel, C. A. Muro-Cacho, and T. J. Yeatman, "Fibrinogen $\gamma$ overexpression in pancreatic cancer identified by large-scale proteomic analysis of serum samples," Cancer Research, vol. 66, no. 5, pp. 2592-2599, 2006.

[92] J. Guo, W. Wang, P. Liao et al., "Identification of serum biomarkers for pancreatic adenocarcinoma by proteomic analysis," Cancer Science, vol. 100, no. 12, pp. 2292-2301, 2009.

[93] A. S. Roberts, M. J. Campa, E. B. Gottlin et al., "Identification of potential prognostic biomarkers in patients with untreated, advanced pancreatic cancer from a phase 3 trial (Cancer and Leukemia Group B, 80303)," Cancer, vol. 118, no. 2, pp. 571-578, 2012.

[94] J. A. Marrero, "Hepatocellular carcinoma," Current Opinion in Gastroenterology, vol. 22, no. 3, pp. 248-253, 2006.

[95] H. E. Blum, "Hepatocellular carcinoma: therapy and prevention," World Journal of Gastroenterology, vol. 11, no. 47, pp. 7391-7400, 2005.

[96] K. A. Gebo, G. Chander, M. W. Jenckes et al., "Screening tests for hepatocellular carcinoma in patients with chronic hepatitis C: a systematic review," Hepatology, vol. 36, no. 5, supplement 1, pp. S84-S92, 2002.

[97] T. Göbel, S. Vorderwülbecke, K. Hauck, H. Fey, D. Häussinger, and A. Erhardt, "New multi protein patterns differentiate liver fibrosis stages and hepatocellular carcinoma in chronic hepatitis C serum samples," World Journal of Gastroenterology, vol. 12, no. 47, pp. 7604-7612, 2006.

[98] S. Kanmura, H. Uto, K. Kusumoto et al., "Early diagnostic potential for hepatocellular carcinoma using the SELDI ProteinChip system," Hepatology, vol. 45, no. 4, pp. 948-956, 2007.

[99] C. Wu, Z. Wang, L. Liu et al., "Surface enhanced laser desorption/ionization profiling: new diagnostic method of HBVrelated hepatocellular carcinoma," Journal of Gastroenterology and Hepatology, vol. 24, no. 1, pp. 55-62, 2009.

[100] L. Chen, D. W. Y. Ho, N. P. Y. Lee et al., "Enhanced detection of early hepatocellular carcinoma by serum SELDI-TOF proteomic signature combined with alpha-fetoprotein marker," Annals of Surgical Oncology, vol. 17, no. 9, pp. 2518-2525, 2010.

[101] J. Cui, X. Kang, Z. Dai et al., "Prediction of chronic hepatitis $\mathrm{B}$, liver cirrhosis and hepatocellular carcinoma by SELDI-based serum decision tree classification," Journal of Cancer Research and Clinical Oncology, vol. 133, no. 11, pp. 825-834, 2007.

[102] R. Goldman, H. W. Ressom, R. S. Varghese et al., "Detection of hepatocellular carcinoma using glycomic analysis," Clinical Cancer Research, vol. 15, no. 5, pp. 1808-1813, 2009.

[103] Z. Tang, R. S. Varghese, S. Bekesova et al., "Identification of Nglycan serum markers associated with hepatocellular carcinoma from mass spectrometry data," Journal of Proteome Research, vol. 9, no. 1, pp. 104-112, 2010.

[104] R. S. Herbst, J. V. Heymach, and S. M. Lippman, "Molecular origins of cancer: lung cancer," New England Journal of Medicine, vol. 359, no. 13, pp. 1367-1380, 2008.

[105] M. V. Infante and J. H. Pedersen, "Screening for lung cancer: are we there yet?" Current Opinion in Pulmonary Medicine, vol. 16, no. 4, pp. 301-306, 2010.
[106] C. Reddy, D. Chilla, and J. Boltax, "Lung cancer screening: a review of available data and current guidelines," Hospital Practice, vol. 39, pp. 107-112, 2011.

[107] W. D. Travis, E. Brambilla, M. Noguchi et al., "International association for the study of lung cancer/American Thoracic Society/European Respiratory Society: international multidisciplinary classification of lung adenocarcinoma: executive summary," Proceedings of the American Thoracic Society, vol. 8, pp. 381-385, 2011.

[108] O. Lababede, M. Meziane, and T. Rice, "Seventh edition of the cancer staging manual and stage grouping of lung cancer: quick reference chart and diagrams," Chest, vol. 139, no. 1, pp. 183-189, 2011.

[109] S. Cedrés, I. Nuñez, M. Longo et al., "Serum tumor markers CEA, CYFRA21-1, and CA-125 are associated with worse prognosis in advanced non-small-cell lung cancer (NSCLC)," Clinical Lung Cancer, vol. 12, no. 3, pp. 172-179, 2011.

[110] J. Chee, A. Naran, N. L. Misso, P. J. Thompson, and K. D. Bhoola, "Expression of tissue and plasma kallikreins and kinin B1 and B2 receptors in lung cancer," Biological Chemistry, vol. 389, pp. 1225-1233, 2008.

[111] E. Wójcik, J. K. Kulpa, B. Sas-Korczyńska, S. Korzeniowski, and J. Jakubowicz, "ProGRP and NSE in therapy monitoring in patients with small cell lung cancer," Anticancer Research, vol. 28, no. 5, pp. 3027-3033, 2008.

[112] S. Y. Yang, X. Y. Xiao, W. G. Zhang et al., "Application of serum SELDI proteomic patterns in diagnosis of lung cancer," $B M C$ Cancer, vol. 5, article 83, 2005.

[113] M. Han, Q. Liu, J. Yu, and S. Zheng, "Detection and significance of serum protein markers of small-cell lung cancer," Journal of Clinical Laboratory Analysis, vol. 22, no. 2, pp. 131-137, 2008.

[114] R. T. Sreseli, H. Binder, M. Kuhn et al., "Identification of a 17-protein signature in the serum of lung cancer patients," Oncology Reports, vol. 24, no. 1, pp. 263-270, 2010.

[115] J. Du, S. Yang, X. Lin et al., "Use of anchorchip-time-of-flight spectrometry technology to screen tumor biomarker proteins in serum for small cell lung cancer," Diagnostic Pathology, vol. 5, article 60, 2010.

[116] X. Zeng, B. L. Hood, M. Sun et al., "Lung cancer serum biomarker discovery using glycoprotein capture and liquid chromatography mass spectrometry," Journal of Proteome Research, vol. 9, no. 12, pp. 6440-6449, 2010.

[117] P. B. Yildiz, Y. Shyr, J. S. M. Rahman et al., "Diagnostic accuracy of MALDI mass spectrometric analysis of unfractionated serum in lung cancer," Journal of Thoracic Oncology, vol. 2, no. 10, pp. 893-901, 2007.

[118] C. Sperti, C. Pasquali, A. Piccoli, and S. Pedrazzoli, "Survival after resection for ductal adenocarcinoma of the pancreas," British Journal of Surgery, vol. 83, no. 5, pp. 625-631, 1996.

[119] C. J. Yeo, J. L. Cameron, T. A. Sohn et al., "Pancreaticoduodenectomy with or without extended retroperitoneal lymphadenectomy for periampullary adenocarcinoma: comparison of morbidity and mortality and short-term outcome," Annals of Surgery, vol. 229, no. 5, pp. 613-624, 1999.

[120] J. D. Christein, M. L. Kendrick, C. W. Iqbal, D. M. Nagorney, and M. B. Farnell, "Distal pancreatectomy for resectable adenocarcinoma of the body and tail of the pancreas," Journal of Gastrointestinal Surgery, vol. 9, no. 7, pp. 922-927, 2005.

[121] K. S. Goonetilleke and A. K. Siriwardena, "Systematic review of carbohydrate antigen (CA 19-9) as a biochemical marker in the diagnosis of pancreatic cancer," European Journal of Surgical Oncology, vol. 33, no. 3, pp. 266-270, 2007. 
[122] D. Liu, L. Cao, J. Yu et al., "Diagnosis of pancreatic adenocarcinoma using protein chip technology," Pancreatology, vol. 9, no. 1-2, pp. 127-135, 2009.

[123] F. Navaglia, P. Fogar, D. Basso et al., "Pancreatic cancer biomarkers discovery by surface-enhanced laser desorption and ionization time-of-flight mass spectrometry," Clinical Chemistry and Laboratory Medicine, vol. 47, no. 6, pp. 713-723, 2009.

[124] A. Xue, C. J. Scarlett, L. Chung et al., "Discovery of serum biomarkers for pancreatic adenocarcinoma using proteomic analysis," British Journal of Cancer, vol. 103, no. 3, pp. 391-400, 2010.

[125] B. K. Bloor, N. Tidman, I. M. Leigh et al., "Expression of keratin K2e in cutaneous and oral lesions: association with keratinocyte activation, proliferation, and keratinization," American Journal of Pathology, vol. 162, no. 3, pp. 963-975, 2003.

[126] S. A. Joosse, J. Hannemann, J. Spötter et al., "Changes in keratin expression during metastatic progression of breast cancer: impact on the detection of circulating tumor cells," Clinical Cancer Research, vol. 18, no. 4, pp. 993-1003, 2012.

[127] X. L. Jin, S. S. Zheng, B. S. Wang, and H. L. Chen, "Correlation of glycosyltransferases mRNA expression in extrahepatic bile duct carcinoma with clinical pathological characteristics," Hepatobiliary and Pancreatic Diseases International, vol. 3, no. 2, pp. 292-295, 2004.

[128] R. Prudent, C. F. Sautel, and C. Cochet, "Structure-based discovery of small molecules targeting different surfaces of protein-kinase CK2," Biochimica et Biophysica Acta, vol. 1804, no. 3, pp. 493-498, 2010.

[129] K. A. Zanetti, M. Haznadar, J. A. Welsh et al., "3'-UTR and functional secretor haplotypes in mannose-binding lectin2 are associated with increased colon cancer risk in African Americans," Cancer Research, vol. 72, no. 6, pp. 1467-1477, 2012.

[130] N. S. Nevadunsky, I. Korneeva, T. Caputo, and S. S. Witkin, "Mannose-binding lectin codon 54 genetic polymorphism and vaginal protein levels in women with gynecologic malignancies," European Journal of Obstetrics \& Gynecology and Reproductive Biology, vol. 163, no. 2, pp. 216-218, 2012.

[131] V. Urquidi, J. Kim, M. Chang, Y. Dai, C. J. Rosser, and S. Goodison, "CCL18 in a multiplex urine-based assay for the detection of bladder cancer," PLoS One, vol. 7, no. 5, article e37797, 2012.

[132] Q. Chen, J. Fei, L. Wu et al., "Detection of cathepsin B, cathepsin $\mathrm{L}$, cystatin $\mathrm{C}$, urokinase plasminogen activator and urokinase plasminogen activator receptor in the sera of lung cancer patients," Oncology Letters, vol. 2, no. 4, pp. 693-699, 2011.

[133] N. Chirwa, D. Govender, B. Ndimba et al., "A 40-50kDa glycoprotein associated with mucus is identified as $\alpha$-1-acid glycoprotein in carcinoma of the stomach," Journal of Cancer, vol. 3, pp. 83-92, 2012.

[134] G. Gruden, P. Carucci, V. Lolli et al., "Serumheat shock protein 27 levels in patients with hepatocellular carcinoma," Cell Stress and Chaperones. In press.

[135] E. Kuhn, T. Addona, H. Keshishian et al., "Developing multiplexed assays for troponin I and interleukin-33 in plasma by peptide immunoaffinity enrichment and targeted mass spectrometry," Clinical Chemistry, vol. 55, no. 6, pp. 1108-1117, 2009.

[136] N. L. Anderson and N. G. Anderson, "The human plasma proteome: history, character, and diagnostic prospects," Molecular \& Cellular Proteomics, vol. 1, no. 11, pp. 845-867, 2002. 

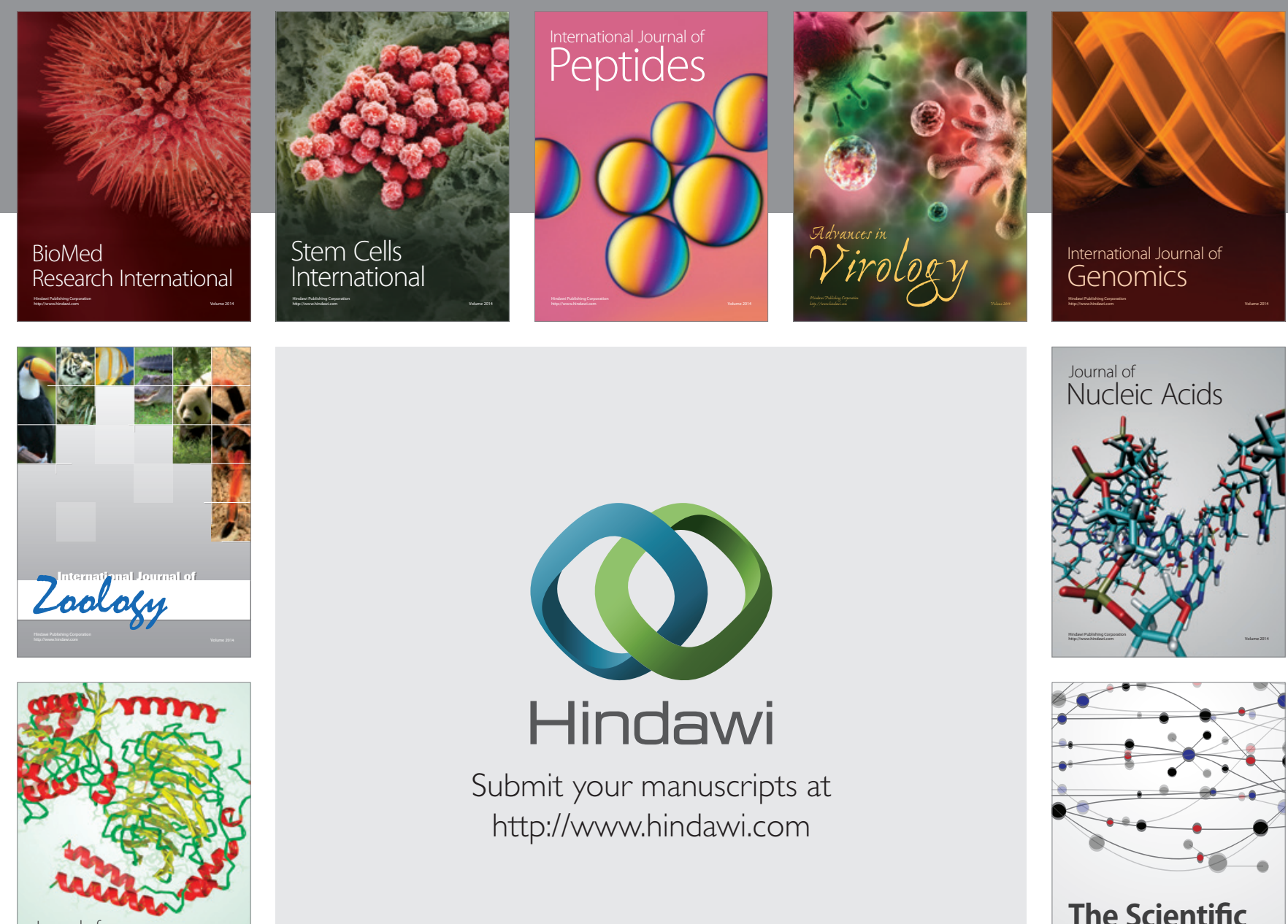

Submit your manuscripts at

http://www.hindawi.com

Journal of
Signal Transduction
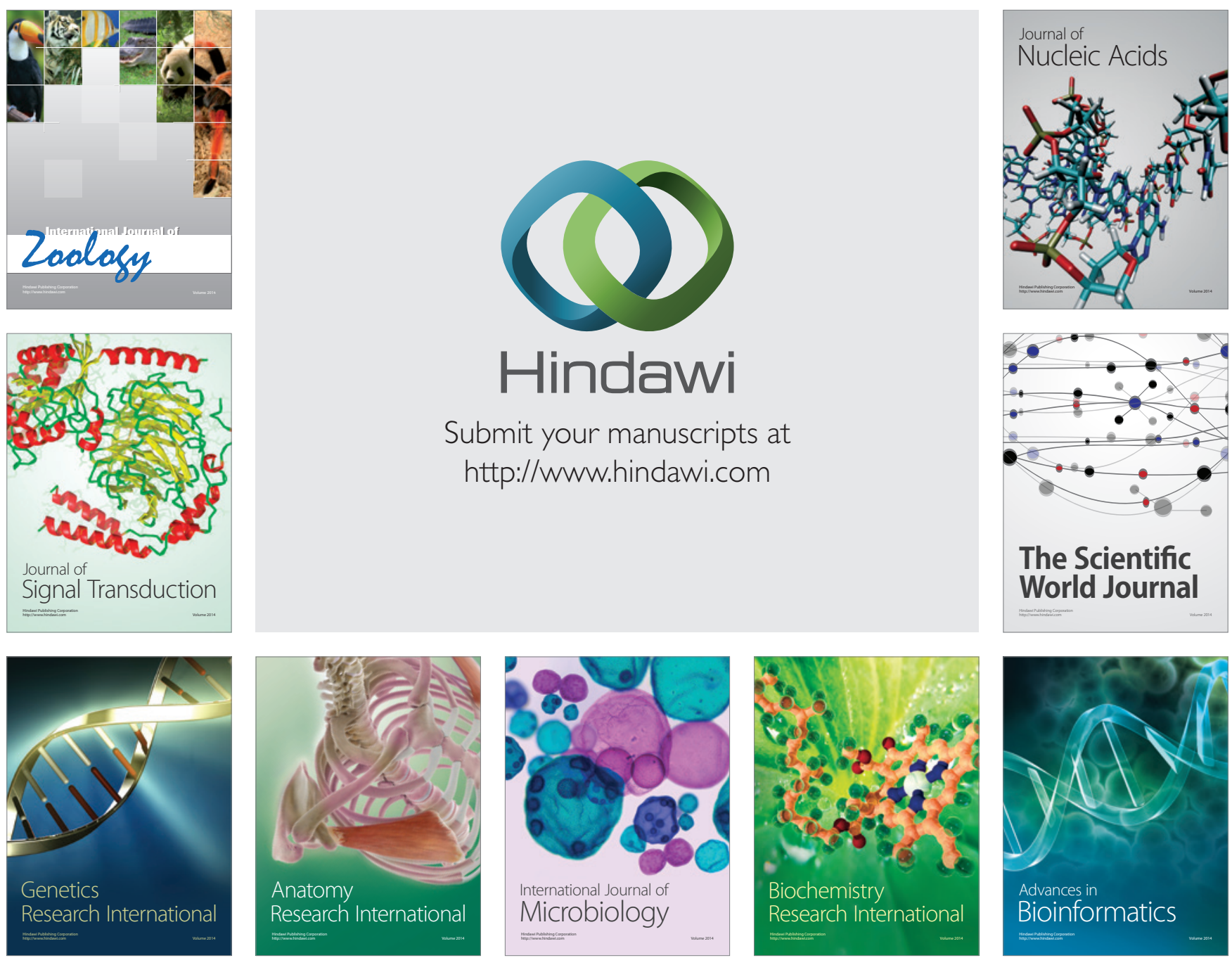

The Scientific World Journal
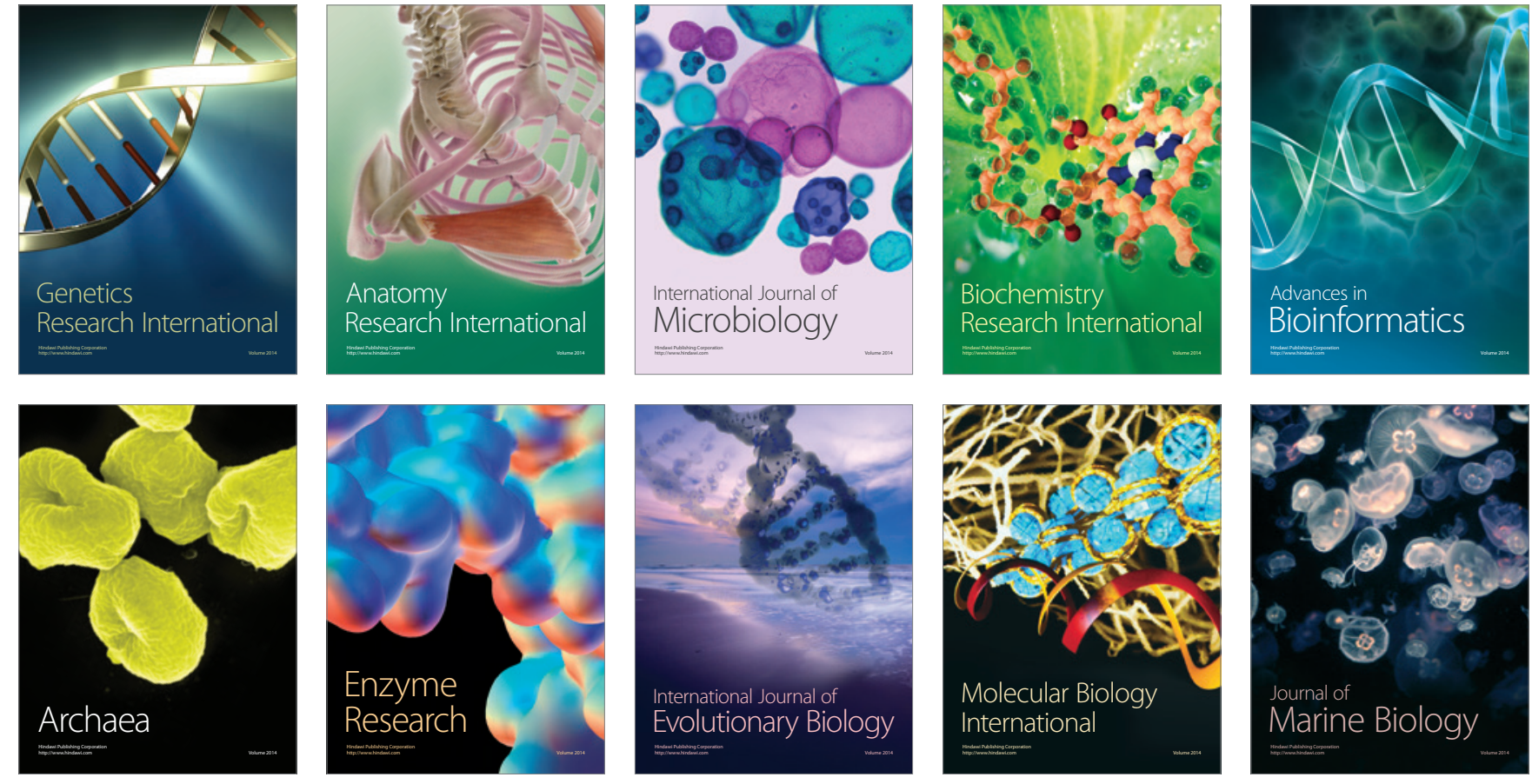